\title{
Integrating pathway elucidation with yeast engineering to produce polpunonic acid the precursor of the anti-obesity agent celastrol
}

\author{
Nikolaj L. Hansen', Karel Miettinen', Yong Zhao ${ }^{1,2}$, Codruta Ignea' ${ }^{1}$, Aggeliki Andreadelli ${ }^{3}$, Morten H. Raadam', \\ Antonios M. Makris ${ }^{3}$, Birger L. Møller ${ }^{1}$, Dan Stærk², Søren Bak ${ }^{{ }^{*}}$ and Sotirios C. Kampranis ${ }^{1 *}$ (D)
}

\begin{abstract}
Background: Celastrol is a promising anti-obesity agent that acts as a sensitizer of the protein hormone leptin. Despite its potent activity, a sustainable source of celastrol and celastrol derivatives for further pharmacological studies is lacking.

Results: To elucidate the celastrol biosynthetic pathway and reconstruct it in Saccharomyces cerevisiae, we mined a root-transcriptome of Tripterygium wilfordii and identified four oxidosqualene cyclases and 49 cytochrome P450s as candidates to be involved in the early steps of celastrol biosynthesis. Using functional screening of the candidate genes in Nicotiana benthamiana, TwOSC 4 was characterized as a novel oxidosqualene cyclase that produces friedelin, the presumed triterpenoid backbone of celastrol. In addition, three P450s (CYP712K1, CYP712K2, and CYP712K3) that act downstream of TwOSC 4 were found to effectively oxidize friedelin and form the likely celastrol biosynthesis intermediates 29-hydroxy-friedelin and polpunonic acid. To facilitate production of friedelin, the yeast strain AM254 was constructed by deleting $U B C 7$, which afforded a fivefold increase in friedelin titer. This platform was further expanded with CYP712K1 to produce polpunonic acid and a method for the facile extraction of products from the yeast culture medium, resulting in polpunonic acid titers of $1.4 \mathrm{mg} / \mathrm{L}$.
\end{abstract}

Conclusion: Our study elucidates the early steps of celastrol biosynthesis and paves the way for future biotechnological production of this pharmacologically promising compound in engineered yeast strains.

Keywords: P450, Terpenoid, Tobacco, Biosynthetic pathway

\section{Background}

Obesity is a major health risk associated with numerous debilitating conditions, including type 2 diabetes, cardiovascular disease and hypertension [1]. Despite intense research, an effective pharmacological treatment of obesity is still lacking. One promising approach involves leptin, an adipocyte-derived protein hormone that sends

\footnotetext{
*Correspondence: bak@plen.ku.dk; soka@plen.ku.dk

1 Plant Biochemistry Section, Department of Plant and Environmental

Sciences, University of Copenhagen, Thorvaldsensvej 40,

1871 Frederiksberg C, Denmark

Full list of author information is available at the end of the article
}

signals that inform the central nervous system on the status of the peripheral energy stores, controlling overall metabolism and food uptake [2, 3]. In obesity, cells become unresponsive to leptin [4-6]. Thus, identifying molecules that alleviate leptin resistance could provide a treatment for the condition. In a large search for leptin sensitizers, the plant specialized metabolite celastrol was identified as the most potent candidate, leading to up to $45 \%$ weight loss in hyperleptinemic diet-induced obese mice [7]. Celastrol was shown to protect against obesity and metabolic dysfunction through activation of the transcription factor HSF1, which regulates metabolic programs in adipose tissue and muscle [8]. Further

c) The Author(s) 2020. This article is licensed under a Creative Commons Attribution 4.0 International License, which permits use, sharing, adaptation, distribution and reproduction in any medium or format, as long as you give appropriate credit to the original author(s) and the source, provide a link to the Creative Commons licence, and indicate if changes were made. The images or other third party material in this article are included in the article's Creative Commons licence, unless indicated otherwise in a credit line to the material. If material is not included in the article's Creative Commons licence and your intended use is not permitted by statutory regulation or exceeds the permitted use, you will need to obtain permission directly from the copyright holder. To view a copy of this licence, visit http://creativeco mmons.org/licenses/by/4.0/. The Creative Commons Public Domain Dedication waiver (http://creativecommons.org/publicdomain/ zero/1.0/) applies to the data made available in this article, unless otherwise stated in a credit line to the data. 
studies showed that celastrol binds specifically to the nuclear receptor Nur77, which may confer the leptinsensitizing effect by regulating HFD-induced hypothalamic inflammation [9]. In addition, celastrol has been found to have a strong protective effect in several other human conditions [10-19].

Celastrol is a red/orange quinone methide nor-triterpenoid found in the root bark of some genera of Celastraceae, including the traditional Chinese medicinal plant Tripterygium wilfordii [20, 21]. However, scalable and reliable sourcing of celastrol or related compounds from plant roots is challenged by slow growth, yield fluctuations and complexity of harvesting branching roots. Furthermore, the production is geographically restricted as the export of T. wilfordii from its natural habitat is regulated by the Nagoya protocol. Although total organic synthesis of celastrol has been reported, it is laborious and inefficient [22]. Thus, sourcing from nature or chemical synthesis does not provide sufficient amounts of pure compound. Therefore, alternative celastrol production methods are needed.

Heterologous reconstruction of biosynthetic pathways in engineered microorganisms is an attractive solution for the sustainable production of structurally complex specialized metabolites. In the case of celastrol, this approach will enable its efficient stereo-specific biosynthesis and the production of derivatives in adequate amounts. The model organism Saccharomyces cerevisiae (baker's yeast) is an established host for the efficient production of industrial chemicals and complex highvalue compounds [23-25]. This is due to its amenability to genetic engineering, relative absence of secondary metabolites, and its compatibility with most key eukaryotic biosynthetic enzymes, such as cytochromes P450
(P450s), enabling the reconstruction of complete biosynthetic pathways.

The ability to produce high-value compounds in engineered microorganisms requires elucidation of the biosynthetic pathway of the compound of interest. To facilitate pathway elucidation, transient gene expression in tobacco (Nicotiana benthamiana) leaves is an efficient tool for in vivo characterization of novel plant biosynthetic enzymes [26-29]. Compared with microbial systems, such as yeast, transient tobacco expression offers a plant molecular environment that may be functionally important for plant-derived enzymes. For example, plants differ from yeast in the lipid composition of the endoplasmic reticulum (ER) membrane [30, 31], which may influence the correct insertion or function of membraneassociated proteins, such as OSCs or P450s. Membrane composition may also affect the transport of hydrophobic specialized metabolites, like terpenes, between different cellular compartments (i.e., chloroplasts and ER), or between membrane-bound enzymes catalyzing successive steps of a pathway. In addition, plants express redox co-factors dedicated to secondary metabolism, such as specialized cytochrome b5 proteins [32], and many CYPs depend on such co-factors for optimal activity.

Celastrol biosynthesis likely adheres to the common triterpenoid scheme that starts with cycloisomerization of 2,3-oxidosqualene by an oxidosqualene cyclase (OSC) and continues with oxidative decoration(s) of the 30-carbon triterpenoid core structure by cytochrome P450 enzymes (Fig. 1) [33, 34]. Downstream of these initial oxygenation steps, other enzyme families such as acyl transferases, dehydrogenases, and 2-oxoglutaratedependent dioxygenases modify plant terpenoids [27, $35,36]$. In the case of celastrol biosynthesis, the core

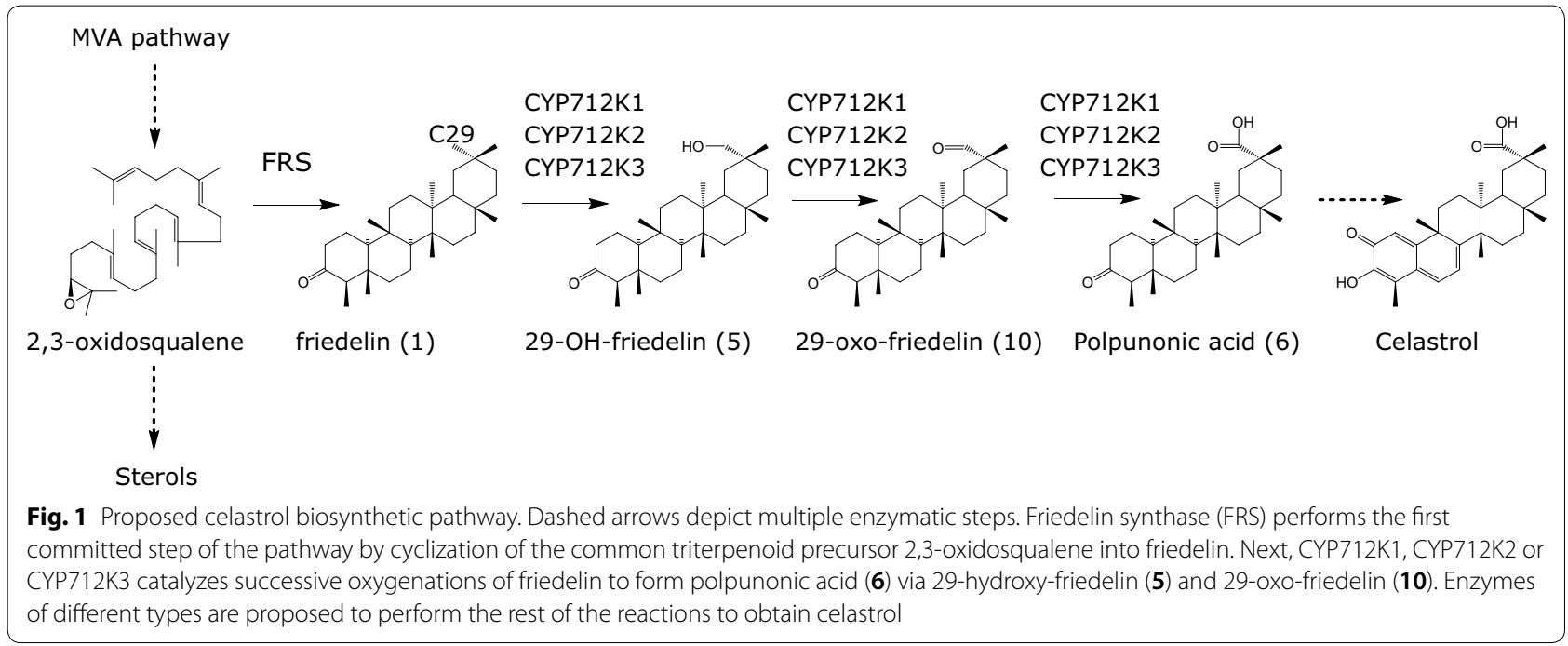


triterpenoid scaffold is thought to be friedelin (1), synthesized by OSC enzymes named friedelin synthases (FRSs) [37, 38]. However, knowledge of the downstream biosynthetic steps is lacking, hindering biotechnological production of celastrol in a cell factory.

Here, we address this challenge by combining pathway elucidation with metabolic engineering to identify missing enzyme activities and establish production of celastrol precursors in an engineered yeast cell factory. We describe the establishment of a platform for the bioproduction of celastrol and related celastroids in yeast through initial enzyme activity screening in tobacco leaves, followed by structural characterization of the produced compounds and construction of efficient yeast production strains that allows for optimization of yeast growth and product extraction. These findings provide a base for future biotechnological production of pharmacologically relevant anti-obesity celastroids.

\section{Results}

\section{Transcriptome mining identified friedelin synthase} candidates

Establishing microbial production of celastrol and its precursors requires elucidation of the biosynthetic pathway and identification of the enzymes involved. To facilitate this, we based our search for candidate biosynthetic genes on transcriptomic data [39] derived from root tissue of $T$. wilfordii confirmed to produce high levels of celastrol (Fig. 2).

The canonical biosynthesis of triterpenoids begins with carbon-backbone formation via cyclization of 2,3-oxidosqualene by an OSC. The dataset was mined for OSC transcripts with the MassBlast transcriptome analysis tool [40], using the Arabidopsis thaliana $\beta$-amyrin synthase [41] (AtBAS; accession: BAG82628) as query sequence. Candidate OSCs were selected on the basis of amino acid sequence similarity with $A t$ BAS (a representative OSC of plant specialized metabolism) and prioritized by relative transcript abundance (Fragments Per Kilobase Million, FPKM). We identified a set of four candidate OSCs and named them TwOSC1 (19 FPKM), TwOSC2 (1 FPKM), TwOSC3 (28 FPKM), and TwOSC4 (245 FPKM), reflecting the order of their similarity with the query sequence. Indication of the expression levels of the four genes assessed by relative transcript numbers (FPKM) highlighted $T w \mathrm{OSC} 4$ as the most abundant OSC transcript.

\section{TwOSC4 synthesizes friedelin in tobacco}

To allow for characterization of the candidate enzymes in a host well-suited for plant enzymes, we chose to
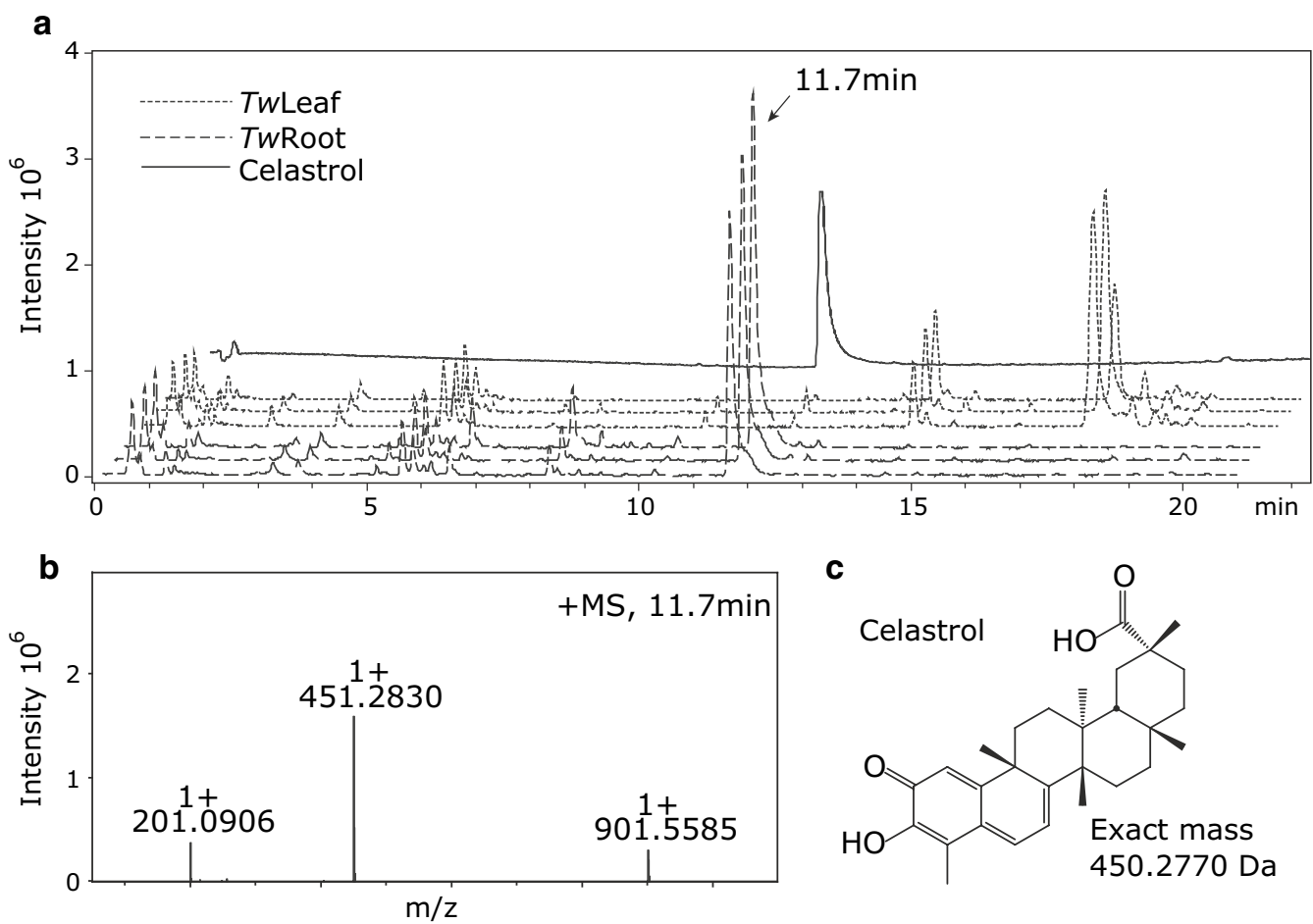

Fig. 2 LC-ESI-MS profiles of methanol extracts of Tripterygium wilfordii root and leaves. a Methanol extracts of root tissue (three biological replicates; dashed line) show a strong peak at $11.7 \mathrm{~min}$ with $\mathrm{m} / \mathrm{z}$ of $451.2830[\mathrm{M}+\mathrm{H}]^{+}$corresponding to celastrol. The identity of the compound was confirmed using a celastrol standard (solid line). b Mass spectrum of celastrol eluting at 11.7 min. c Structure of celastrol 
express the OSC candidates by Agrobacterium-mediated transient expression in tobacco. Tobacco cells naturally provide endogenous 2,3-oxidosqualene, the archetypical substrate of OSCs, and the physiologically-relevant cellular environment to handle the highly hydrophobic OSC products. The full-length coding sequences of the four candidate synthases were amplified from $T$. wilfordii root cDNA by PCR and cloned into the A. tumefaciens binary vector pCAMBIA-1300-35Su [42]. Following transient expression of the individual candidate OSCs, we traced the apolar metabolite profile of tobacco leaves by GC-MS analysis of both hexane extracts or derivatized residues of dried ethyl acetate extracts (to cover both derivatizable and non-derivatizable compounds). When compared to an empty vector control, all four candidates yielded novel peaks in the GC-MS analysis (Fig. 3a). Transient expression of one of the candidates, TwOSC4, resulted in a predominant peak that corresponded to friedelin, as identified by comparison of retention time and mass spectrum to an authentic standard (Fig. 3a, b).
Only a minor additional new peak was observed in the chromatogram for TwOSC4, which, however, also appeared in the friedelin standard, suggesting that TwOSC4 is a highly product specific friedelin synthase. Transient expression of TwOSC1 and TwOSC2 resulted in new peaks with the same retention time and mass spectra as an authentic $\beta$-amyrin (2) standard (Fig. 3a and Additional file 1: Figure S1). The remaining synthase, TwOSC3, produced mainly $\alpha$-amyrin (3) together with relative lower amounts of $\beta$-amyrin (2), as confirmed by comparison to authentic standards. In addition, TwOSC2 also produced minor amounts of lupeol (4).

\section{Transcriptome mining identified 49 candidate CYPs}

Celastrol carries several oxidative decorations on its core structure (Fig. 2). To identify the enzymes catalyzing these oxygenations, we targeted the large family of plant P450s as they are commonly associated with carbon oxygenations of hydrophobic molecules. 49 candidate P450 genes were selected based on homology with
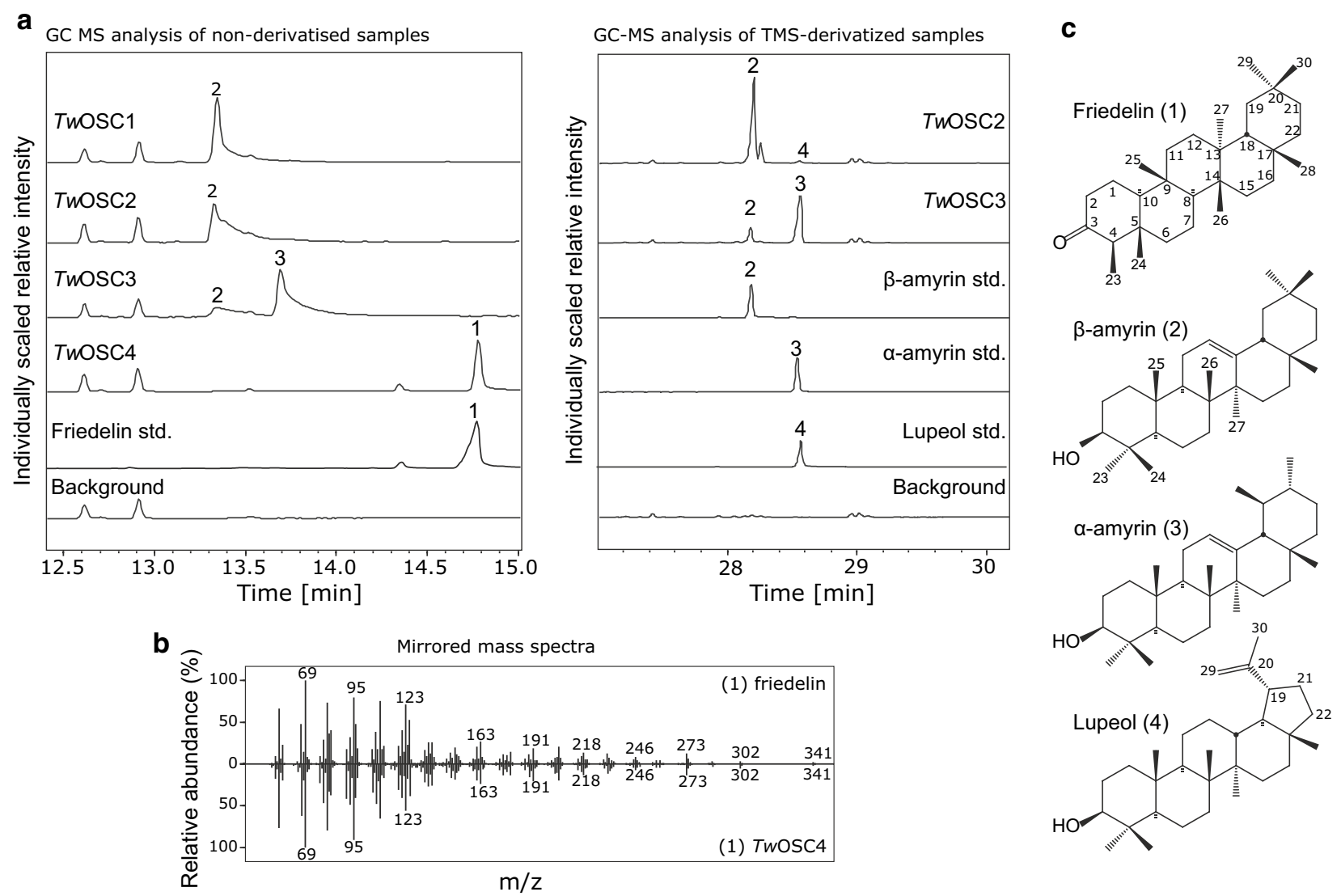

Fig. 3 Characterization of T. wilfordii candidate oxidosqualene cyclases by transient expression in tobacco. a Two discs ( $\varnothing 3 \mathrm{~cm})$ of leaves expressing the indicated enzymes were extracted in $1 \mathrm{~mL}$ hexane (left panel) or $1 \mathrm{~mL}$ ethyl acetate (right panel) and analyzed by GC-MS either directly (left panel) or after solvent evaporation (of $0.15 \mathrm{~mL}$ aliquots) and trimethylsilyl cyanide derivatization (right panel). Major products were established by comparison of mass spectra and retention time to authentic standards (see also Additional file 1: Figure S1). b Comparison of the mass spectrum of friedelin standard with the spectrum of the main product of TwOSC4. c Structures and selected carbon numbering of the products 
known terpene-targeting $\mathrm{P} 450 \mathrm{~s}$ and by displaying relatively high FPKM values. Of these candidates, 42 P450 candidates were identified from the previously reported T. wilfordii root transcriptome [39]. The remaining seven candidates were selected from an earlier published leaf transcriptome of $T$. wilfordii [43]. The P450 candidates were assigned names by Professor David Nelson (University of Tennessee, USA) according to the P450 nomenclature system. P450 families typically associated with specialized metabolite biosynthesis were well represented in the list of candidates including, among others, nine members of the CYP71 family, 14 members the CYP88 family and nine members of the CYP82 family (P450 names listed in Additional file 1: Table S1).

\section{CYP712K1, CYP712K2 and CYP712K3 oxygenate friedelin}

The 49 selected $\mathrm{P} 450$ candidates were cloned into appropriate vectors for biochemical analysis using transient expression in tobacco leaves. Following agrobacterium mediated co-infiltration of tobacco leaves with candidate P450s and friedelin synthase (TwOSC4), the ability of each $\mathrm{P} 450$ to oxygenate friedelin was evaluated by GC-MS analysis of TMS derivatized leaf-extracts. We identified three P450s of the CYP712 family (CYP712K1, CYP712K2 and CYP712K3), which, when co-expressed with TwOSC4, caused the appearance of two novel constituents, corresponding to compounds $\mathbf{5}$ and $\mathbf{6}$, in conjunction with significant reduction of friedelin. The levels and ratio of the novel constituents varied depending on the P450 enzyme (Fig. 4), with CYP712K1 favoring formation of $\mathbf{6}$ and CYP712K2 favoring formation of 5. CYP712K3 also favored production of $\mathbf{5}$, albeit to a lesser extent. The combined effect of the three P450s on the product profile was assessed by co-expressing the three possible two-P450 combinations and all three P450s together in the presence of TwOSC4 (Fig. 4). These combinations revealed that CYP712K1 consistently determined the product ratio in favor of $\mathbf{6}$, independently of the presence of the other two CYP712s. This finding was interpreted as either a consequence of CYP712K1 having greater affinity for the substrate, or simply 5 being an intermediate en route to $\mathbf{6}$. Since no additional products were observed when any two of the three P450s were combined, we concluded that these enzymes must have the same regiospecific activities. To evaluate the substrate promiscuity of the isolated enzymes, the ability of CYP712K1 and CYP712K2 to oxygenate $\alpha$ - or $\beta$-amyrin by agrobacterium mediated co-infiltration with TwOSC3and TwOSC2-were evaluated (Additional file 1: Figure S2). Both enzymes oxygenated $\beta$-amyrin to products 7 and $\mathbf{8}$, which may be consecutive oxygenation products of the $\beta$-amyrin scaffold. CYP712K2, but not CYP712K1, was also able to oxygenate $\alpha$-amyrin to compound 9.

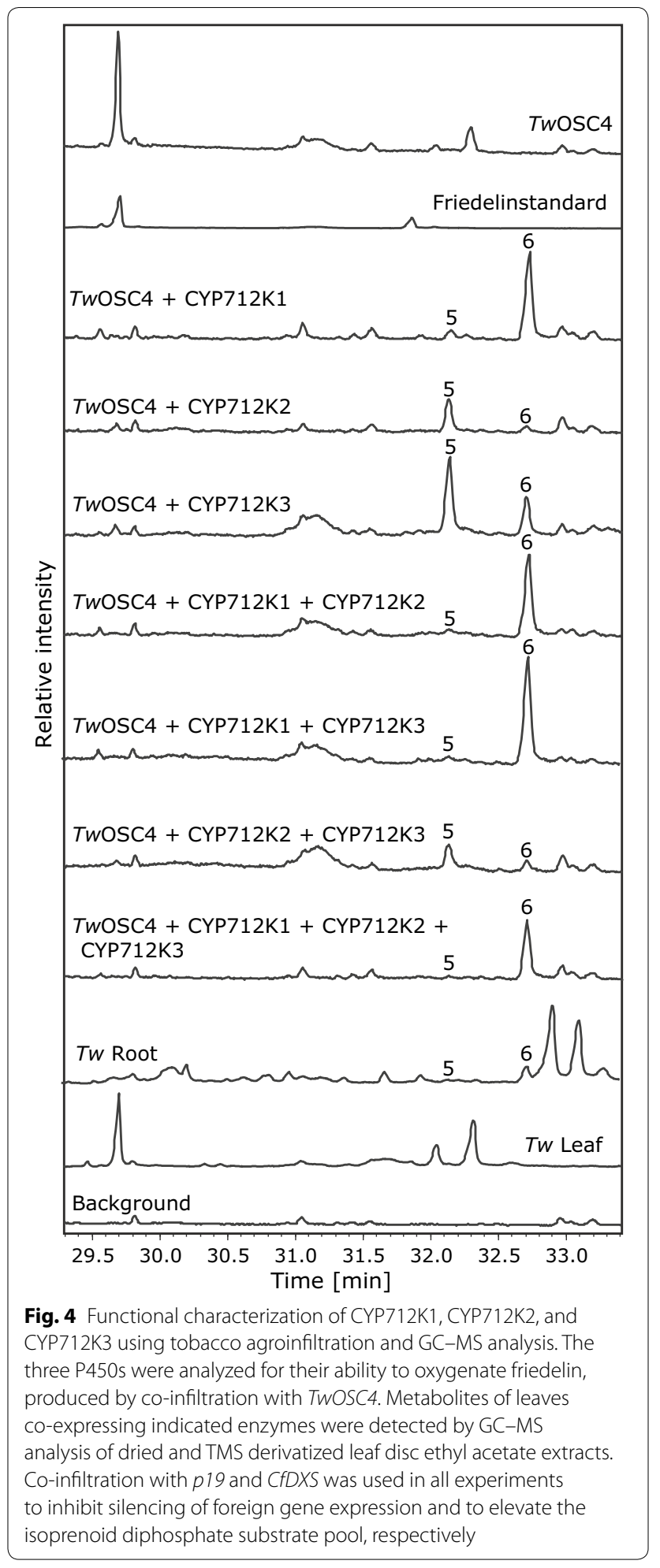

Since these products are unlikely to be intermediates of the celastrol pathway, they were not studied further.

To investigate the existence of friedelin and compounds representing peaks 5 and $\mathbf{6}$ in roots and leaves 
of $T$. wilfordii, plant extracts of these tissues were also analyzed by GC-MS (Fig. 4). Both 5 and $\mathbf{6}$, but not friedelin, were detected in the root extract. By contrast, compounds $\mathbf{5}$ and $\mathbf{6}$ were not observed in the leaves, which, on the other hand, accumulated friedelin. This is consistent with friedelin being specifically converted to celastrol and related compounds in the roots.

\section{Structural elucidation of the CYP712K1, CYP712K2 and CYP712K3-catalyzed products}

To confirm that the products formed by the action of the TwOSCs and CYP712K1, CYP712K2 and CYP712K3 were indeed celastrol precursors, the structures of the novel compounds $\mathbf{5}$ and $\mathbf{6}$ were elucidated. First, exact mass determination was obtained by liquid chromatography-electrospray ionization mass spectrometry (LC-ESI-MS; Fig. 5). The accurate mass to charge ratio of was $443.3853 \mathrm{~m} / \mathrm{z}[\mathrm{M}+\mathrm{H}]^{+}$for compound 5 and $457.3674 \mathrm{~m} / \mathrm{z}[\mathrm{M}+\mathrm{H}]^{+}$for compound 6, corresponding to an approximate $\mathrm{m} / \mathrm{z}$ gain of 16 and 30, respectively, compared to friedelin (predicted $\mathrm{m} / \mathrm{z} 427.3940[\mathrm{M}+\mathrm{H}]^{+}$). These mass gains are consistent with the formation of $\mathbf{5}$ and $\mathbf{6}$ by a single and two oxygenations, respectively. Such oxygenations could correspond to a carbon hydroxylation $(+16)$ and an additional oxygenation of a carbonyl into a carboxyl group $(+30)$. These results suggest that these P450 enzymes likely catalyze three sequential oxygenations of friedelin into an alcohol, and further to a carboxylic acid via an aldehyde. This mechanism is consistent with the action of other diterpene and triterpene modifying P450s that catalyze three successive oxidation steps on the same carbon [44-46].

In order to unambiguously elucidate the structure of compounds 5 and $\mathbf{6}$ using NMR, we isolated these compounds from large-scale agro-infiltration experiments in tobacco (48 plants for each compound). To preferentially produce compound $\mathbf{5}$, tobacco plants were co-infiltrated with TwOSC4 and CYP712K3. To produce compound 6, TwOSC4 and CYP712K1 were co-infiltrated. In both cases together with the $p 19$ suppressor of silencing and the gene encoding 1-deoxy-d-xylulose 5-phosphate synthase CfDXS. NMR analysis of the isolated compounds and comparison to previously reported data $[47,48]$ identified compound $\mathbf{5}$ as 29-hydroxy-friedelin and compound $\mathbf{6}$ as polpunonic acid (29-carboxy-friedelin; Fig. 1, Additional file 1: Table S3). Combined with our GC-MS and LC-ESI-MS results, and the combinatorial experiment in the section above describing the functional analysis of the different CYP712K enzymes, these findings confirm that all three enzymes catalyze the three-step

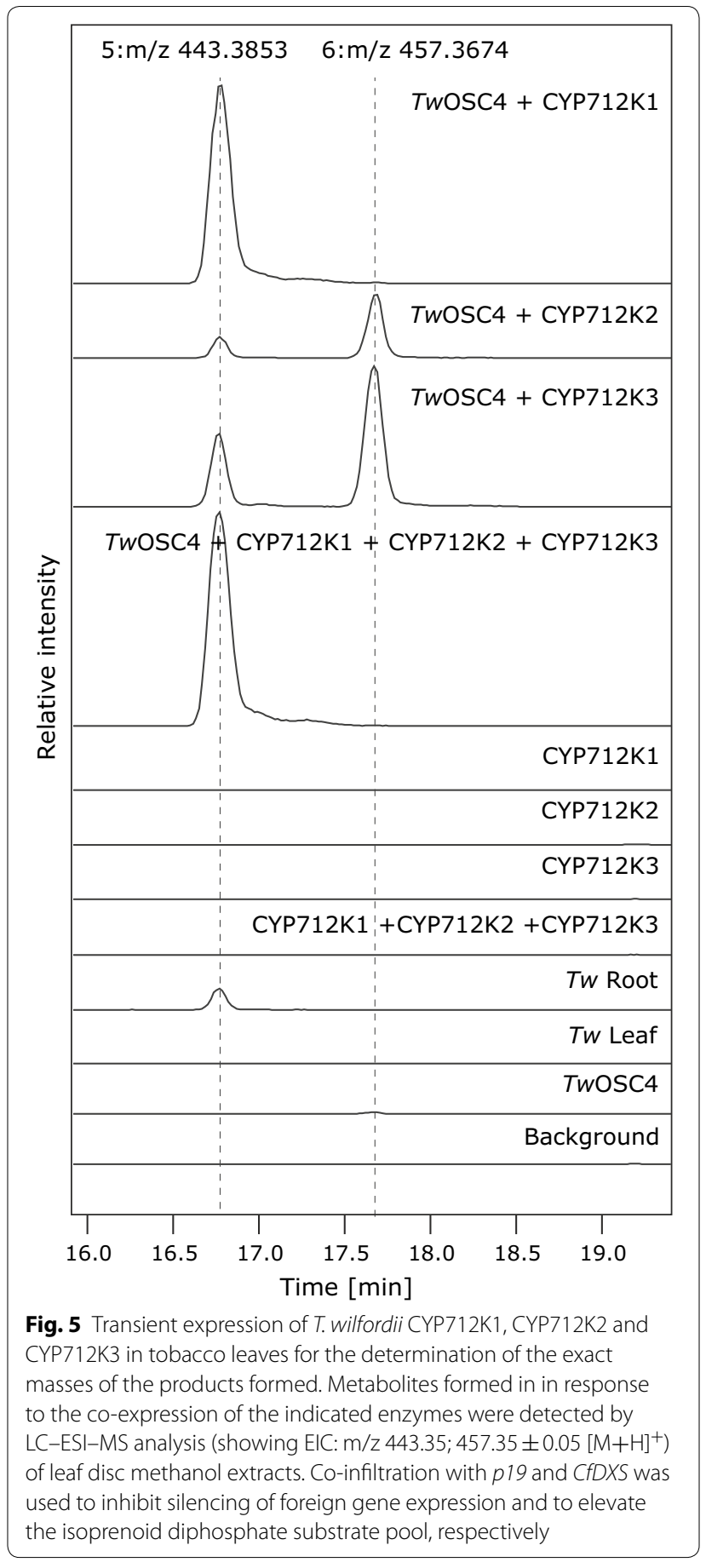

oxygenation of C-29 of friedelin to form polpunonic acid through 29-hydroxyfriedelin and 29-oxofriedelin (Fig. 1).

\section{Friedelin production in yeast}

Having identified biosynthetic enzymes able to produce polpunonic acid (6), we set out to reconstitute the pathway in S. cerevisiae, and to establish a platform 
for the heterologous production of various celastroids. To establish friedelin production in yeast, the gene encoding the $T$. wilfordii friedelin synthase $T w O S C 4$ was cloned into the yeast expression plasmid pUUS and introduced into the diploid yeast strain AM109, specifically designed for terpenoid production [49] (Table 1), resulting in strain AM109-2. Following galactose induction and growth, the yeast cells were disrupted by saponification, extracted with hexane and the organic extract analyzed by GC-MS. However, we were unable to detect production of friedelin despite being able to observe production of another related triterpene, $\alpha$-amyrin, by the Salvia pomifera $\alpha$-amyrin synthase (SpAS1) [50] under the same conditions, suggesting that $T w \mathrm{OSC} 4$ may not be active in this yeast system.

Two other friedelin synthases have been reported in the literature. MiFRS was identified in the closely related plant Maytenus ilicifolia [37] and $K d$ FRS, in the less-related Kalanchoe daigremontiana [51]. Accordingly, KdFRS was selected as a surrogate for TwOSC4 for the reconstitution of the early celastrol pathway in yeast, as it was previously shown to produce friedelin in yeast [51]. A synthetic DNA fragment encoding a yeast codon optimized version of $K d$ FRS was cloned into the yeast expression vector pUUS downstream from an inducible promoter and introduced into the strain AM109 (giving rise to strain AM109-3). GCMS analysis and comparison to an empty vector control strain (AM109-1) showed the appearance of a new constituent with the same retention time and mass spectrum as the authentic friedelin standard (Fig. 6a, b), thus confirming friedelin production in yeast by KdFRS.

\section{Improving friedelin production by boosting precursor supply}

Following establishing friedelin production in yeast by the heterologous expression of $K d \mathrm{FRS}$, we set out to improve friedelin production titers. To this end, different engineered haploid and diploid yeast strains were tested for their ability to produce higher amounts of friedelin. In addition to strain AM109, AM238 was chosen because comparative analysis showed that this strain provided enhanced precursor supply for terpenoid production [52]. AM238 is a haploid strain that contains six deletions, rox 1, dos $2, y e r 134 c, v b a 5, y n r 063 w$, and $y g r 259 c$, identified in an iterative genetic screen to boost terpenoid production. An additional strain was constructed by further engineering of AM238 to target the regulation of isoprenoid precursor biosynthesis. Specifically, the heterozygous deletion of $U B C 7$, a ubiquitin conjugating enzyme part of the ERAD (endoplasmic reticulum associated protein degradation) machinery [53] had previously successfully been used to improve FPP-based terpene biosynthesis in yeast [49]. Thus, we aimed to develop an improved strain for triterpenoid production by deleting the $U B C 7$ gene from strain AM238 to produce strain AM254, essentially stacking the beneficial mutations.

Initial analysis of the formation of friedelin and its P450 oxygenation products was performed by GC-MS and LC-ESI-MS (electrospray ionization). To more accurately quantify the content of friedelin based on its molecular ion (Additional file 1: Figure S3), a method

Table 1 Yeast strains used in this study

\begin{tabular}{|c|c|c|}
\hline Strain & Description & Source \\
\hline AM109 & $\begin{array}{l}\text { Mat a/a, } \mathrm{P}_{\text {GAL1 }} \text {-HMG2(K6R):: HOX2, ura3, trp1, his3, } \mathrm{P}_{T D H 3}-\mathrm{HMG} 2(\mathrm{~K} 6 \mathrm{R}) \mathrm{X} 2-: . / \mathrm{eu} 2, \text { ERG9/erg9, UBC7/ubc7, SSM4/ } \\
\text { ssm4, PHO86/pho86 }\end{array}$ & Ignea et al. [49] \\
\hline AM109-1 & AM109; pUUS(empty vector) & This study \\
\hline AM109-2 & AM109; pUUS(TwOSC4) & This study \\
\hline AM109-3 & AM109; pUUS(KdFRS) & This study \\
\hline AM238 & MATa his3, ura3, trp1, rox1, dos2, yer134c, vba5, ynr063w, ygr259c & Trikka et al. [50] \\
\hline AM238-1 & AM238; pUUS(empty vector) & This study \\
\hline AM238-2 & AM238; pUUS(KdFRS) & This study \\
\hline AM254 & AM238; ucb7 & This study \\
\hline AM254-1 & AM254; pUUS(empty vector) & This study \\
\hline AM254-2 & AM254; pUUS(KdFRS) & This study \\
\hline AM254-3 & AM254; pUUS(empty vector); pHTDH(SctHMG2); pESC-LEU(empty vector), pESC-TRP(empty vector) & This study \\
\hline AM254-4 & AM254; pUUS(KdFRS); pHTDH(SctHMG2); pESC-LEU(empty vector); pESC-TRP(empty vector) & This study \\
\hline AM254-5 & AM254; pUUS(KdFRS); pHTDH(SctHMG2); pESC-LEU(TwCPR1); pESC-TRP(CYP712K1) & This study \\
\hline AM254-6 & AM254; pUUS(KdFRS); pHTDH(SctHMG2); pESC-LEU(TwCPR1); pESC-TRP(CYP712K2) & This study \\
\hline AM254-7 & AM254; pUUS(KdFRS); pHTDH(SctHMG2); pESC-LEU(TwCPR1); pESC-TRP(CYP712K3) & This study \\
\hline
\end{tabular}



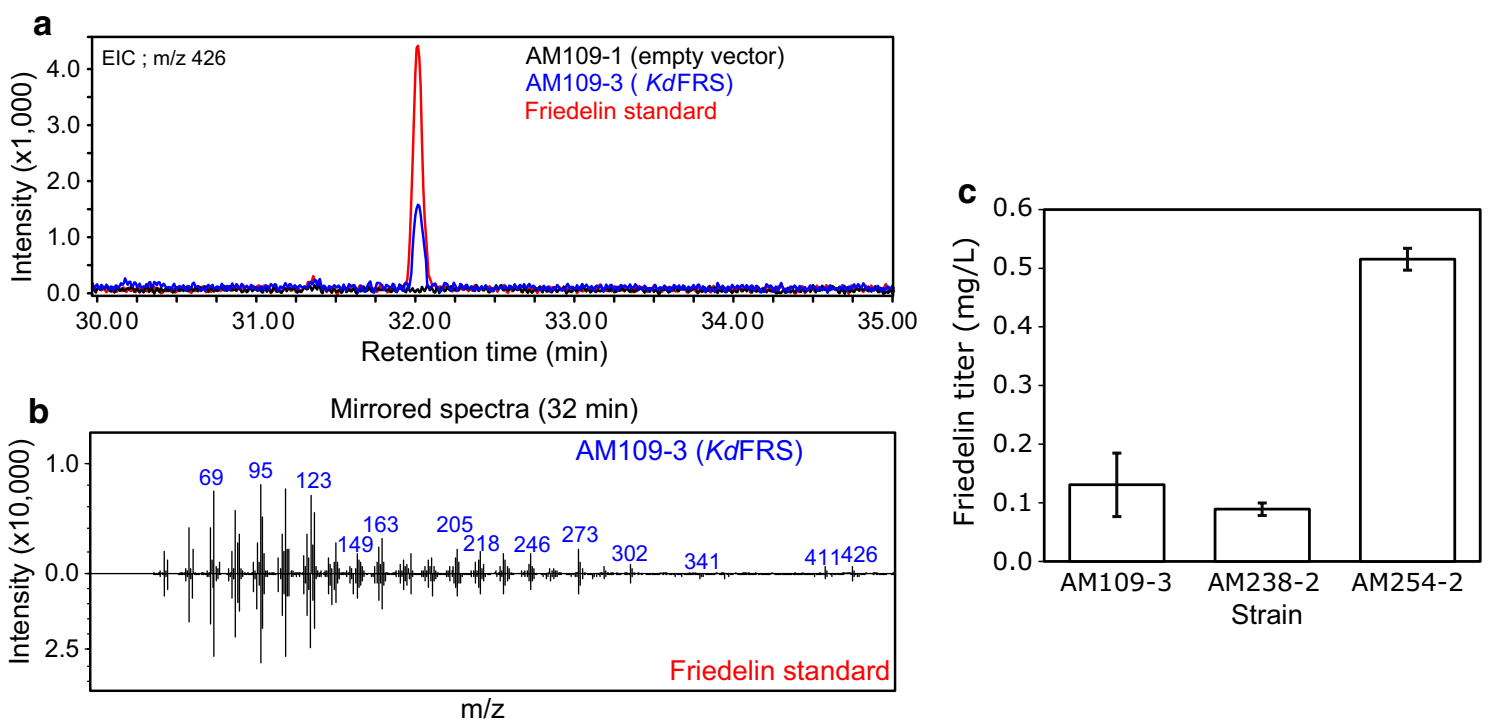

Fig. 6 Functional analysis of KdFRS in yeast. a Comparison of extracted ion GC-MS chromatograms at $\mathrm{m} / \mathrm{z} 426$ (friedelin parent mass) of hexane extracts of the strains AM109-3 (KdFRS, blue), control strain AM109-1 (empty vector, black), and authentic friedelin standard (red), showing accumulation of friedelin in AM109-3. b The constituent eluting at 32 min retention time shows the same mass spectrum as the friedelin standard. c Friedelin accumulation in yeast strains engineered for terpenoid production. Total friedelin production in the strains AM109-3, AM238-2 and AM254-2 expressing KdFRS was quantified by LC-APCI-MS analysis of hexane extracts of saponified cell pellets. $(n=3$, error bars correspond to standard deviation.)

using atmospheric pressure chemical ionization (LCAPCI-MS) was developed.

The different engineered strains were compared for their ability to produce friedelin using the developed LC-APCI-MS analytic methods. The friedelin titer in strains AM109-3, AM238-2 and AM254-2, each harboring a plasmid expressing KdFRS under the control of a galactose inducible promoter (PGAL1) were quantified and compared. Empty vector containing cells (AM1091, AM238-1, or AM254-1) were used as control. After culturing, the cells and spent media were separated by centrifugation and analyzed separately. The pelleted cells were disrupted by saponification and extracted with hexane, while the spent media were directly extracted by hexane. Subsequent analysis of the extracts showed that friedelin was present only inside the cells and not detected in the culture medium. Comparison of the different strains revealed that strain AM254-2 produced approximately $0.5 \mathrm{mg} / \mathrm{L}$ of friedelin, 5 times more friedelin than AM238-2 $(0.1 \mathrm{mg} / \mathrm{L})$ and 4 times more than AM109-3 (0.12 mg/L; Fig. 6c). Thus, UBC7 deletion had a profound effect on friedelin productivity and, therefore, strain AM254 was used as a basis for the subsequent polpunonic production efforts.

\section{Production of polpunonic acid in yeast}

Having established friedelin production in yeast, the next step was to synthesize polpunonic acid and other oxygenated fridelanes by co-expressing the three identified P450s in the same system. For catalysis, P450s require cytochrome $\mathrm{P} 450$ reductases (CPRs) as a redox partner. While the yeast CPR (Ncp1p) is known to complement heterologous P450s, using plant CPRs usually results in higher activities in yeast [24]. Accordingly, a T. wilfordii gene encoding a CPR (TwCPR1) was amplified from cDNA and inserted into the inducible plasmid pESCLEU. In addition, a constitutive expression plasmid, $\mathrm{pHTDH}(\mathrm{tHMG} 2)$ was included, at it drives the production of an N-terminally truncated form of Hmg2p, known to greatly enhance the heterologous production of triterpenoids in yeast [52]. CYP712K1, 2 or 3 were introduced into this system by transforming with the galactoseinducible expression vectors pESC-TRP(CYP712K1), pESC-TRP(CYP712K2), pESC-TRP(CYP712K3), giving rise to strains AM254-5, AM254-6, and AM254-7, respectively.

The combination KdFRS and CYP712K1 (strain AM254-5) resulted in a total (pellet + media) production of $\sim 0.5 \mathrm{mg} / \mathrm{L}$ polpunonic acid (Fig. 7a). Markedly, friedelin and polpunonic acid were found exclusively inside the cells. Production of polpunonic acid resulted in a significant reduction of intracellular friedelin content to 

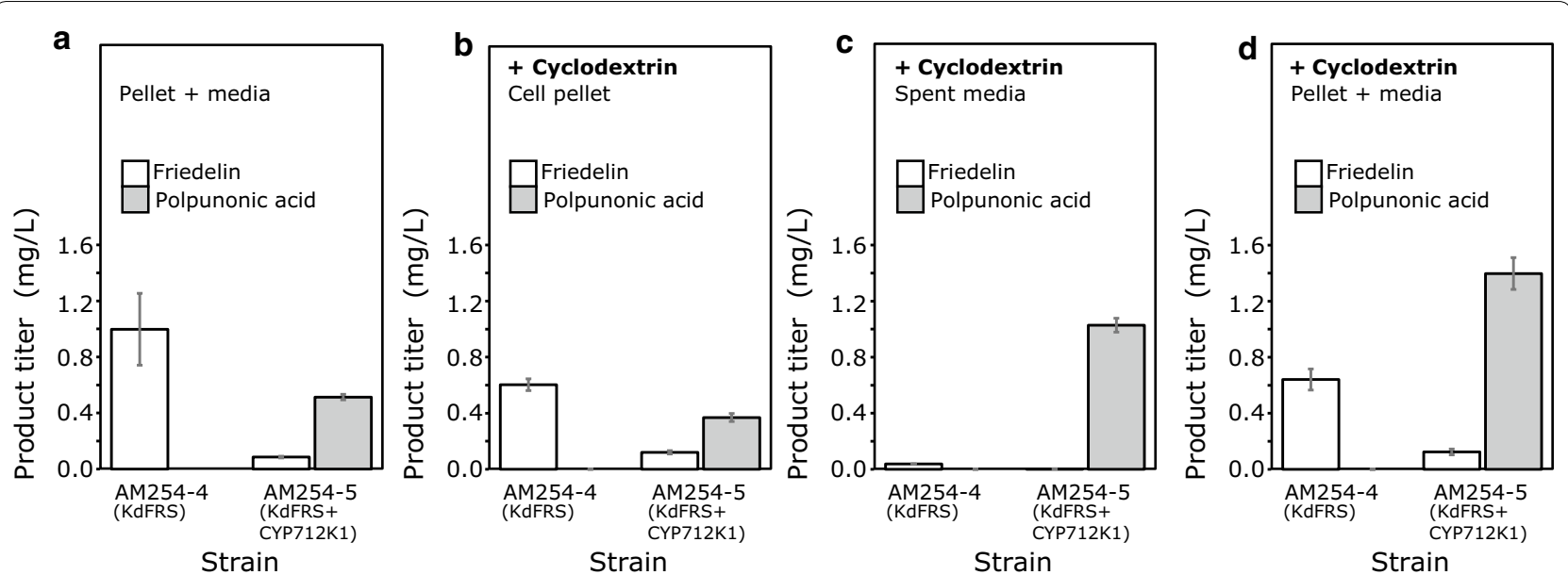

Fig. 7 Production of friedelin and polpunonic acid in yeast strains AM254-4 and AM254-5. a Total accumulation friedelin (white columns) and polpunonic acid (grey columns) in yeast cell cultures without the addition of cyclodextrins (pellet + media). No friedelin or polpunonic acid were found in the media. $\mathbf{b}$ Accumulation of friedelin and polpunonic acid in the cell pellets of cyclodextrin-treated cultures. $\mathbf{c}$ Friedelin and polpunonic acid content in spent media of cyclodextrins-treated cultures. $\mathbf{d}$ Total content (pellet and media) of friedelin and polpunonic acid in cyclodextrin-treated cultures. ( $n=3$, error bars correspond to standard deviation)

$0.1 \mathrm{mg} / \mathrm{L}$, indicating efficient conversion of the precursor. Expression of the other two P450s, did not produce detectable amounts of polpunonic acid, suggesting that CYP712K2 and CYP712K3 were likely less active or less stable when expressed in yeast under the conditions tested.

In order to further improve the production of polpunonic acid, the effect of addition of cyclodextrins to the yeast media was evaluated. Cyclodextrins are macrocyclic oligosaccharides that consist of 6,7 or $8 \alpha-1,4$-linked glucose moieties. Especially methyl- $\beta$-cyclodextrin has previously been shown to stimulate the production of different triterpenoids in yeast [54]. In addition, the use of methyl- $\beta$-cyclodextrin in yeast growth media also offers a convenient way to extract triterpenoids from the spent media [54]. The developed strains were grown in the presence of $10 \mathrm{mM}$ methyl- $\beta$ cyclodextrin to explore whether this would improve polpunonic acid titers. Methyl- $\beta$ cyclodextrin did not improve the titer of friedelin when CYP712K1 was not present, rather, a small decrease was observed (Fig. 7b). Friedelin remained mostly intracellular and addition of methyl- $\beta$-cyclodextrin sequestered less than $5 \%$ of total friedelin in the medium (Fig. 7c). On the other hand, polpunonic acid production was clearly improved in the presence of methyl- $\beta$-cyclodextrin. The titer of total polpunonic acid (pellet + media) increased by 2.8 -fold, from $0.5 \mathrm{mg} / \mathrm{L}$ in the absence to $1.4 \mathrm{mg} / \mathrm{L}$ in the presence of methyl- $\beta$-cyclodextrin (Fig. $7 \mathrm{~d}$ compared with Fig. 7a, where no polpunonic acid was found in the media without cyclodextrin) Thus, there was a clear effect of methyl- $\beta$-cyclodextrin in the efficiency of polpunonic acid, but not friedelin, export from the cells, since in the presence of methyl- $\beta$-cyclodextrin, the majority of polpunonic acid was found in the medium (Fig. 7b, c). The amount of polpunonic acid that remained inside the cells was comparable to the amount found in the pellet in the absence of methyl- $\beta$-cyclodextrin (7A), suggesting that extraction of the product by cyclodextrins may also facilitate the turnover of friedelin oxygenation by CYP712K1. Compared to the cells not expressing CYP712K1 (strain AM254-4), strain AM254-5 showed again reduced levels of friedelin (Fig. 7b-d), indicating higher turnover of friedelin to oxygenated products also in the presence of methyl- $\beta$-cyclodextrin.

\section{Discussion}

In this study, we developed a platform for the production of polpunonic acid in yeast by integrating enzyme discovery using transient co-expression in tobacco plants with the engineering of a yeast production strain and a cyclodextrin based extraction method. As no genes involved in celastrol biosynthesis in T. wilfordii had previously been identified, we started by undertaking a broad gene mining approach to source a catalogue of candidate biosynthetic genes from available transcriptomic data. The first step in celastrol biosynthesis is the cyclization of 2,3-oxidosqualene to produce friedelin by an OSC enzyme. However, enzymes of this class, especially those involved in plant specialized metabolism, are known to often produce more than one products and very rarely can their product profile be predicted from their sequence [33]. Thus, we searched for sequences showing sequence 
similarity with a well-characterized OSC involved in specialized metabolism, the $A$. thaliana $\beta$-amyrin synthase, AtBAS [41] and selected four candidates for further characterization. By transient expression in tobacco, we identified one of the four candidates, TwOSC4, to be a friedelin synthase. While the preparation of this manuscript was in progress, three OSCs from T. wilfordii cell suspension cultures (Genbank accession KY885467, KY885468 and KY885469) were published [55]. In agreement with our data, they were found to encode for $\beta$-amyrin, $\alpha$-amyrin and friedelin synthase activities, respectively.

In triterpenoid biosynthesis, the formation of a triterpene backbone is usually followed by oxidations catalyzed by $\mathrm{P} 450$ enzymes [33]. We selected 49 candidate $\mathrm{P} 450$ s representing 13 different $\mathrm{P} 450$ families known to be involved, or related to families involved, in the biosynthesis of terpenoids (Additional file 1: Table S1). Here, a broad choice of candidates proved to be crucial, since the P450s identified to catalyze the first oxidation in celastrol biosynthesis (CYP712K1, CYP712K2 and CYP712K3) are the first enzymes belonging to the CYP712 family to be characterized. This family was included in the selection because it had previously been linked to triterpenoid biosynthesis through gene-cluster association, co-expression analysis and RNAi studies [56-58]. Moreover, the CYP712 family is also phylogenetically related to the CYP705 family, which contains P450s known to be involved in triterpenoid biosynthesis in Arabidopsis [57]. Nevertheless, a CYP712 family enzyme functional in triterpenoid oxidation had not been reported before. Thus, our findings illuminate the function of one more family of plant P450s.

Yeast is generally regarded as a suitable host for enzymes of plant origin [24]. However, several factors, including differences in intracellular $\mathrm{pH}[59,60]$, membrane lipid composition of the ER [30,31] (relevant for ER-membrane-anchored OSCs and P450s), and availability of dedicated co-factors, such as, for example, specialized cytochrome b5 enzymes [32], are generally regarded to cause a plant enzyme not to function properly in a yeast cell. To minimize the risk of failing to identify enzymes in the celastrol pathway because of suboptimal conditions, we performed functional screening of enzymes by transient co-expression in tobacco. This approach proved successful, as the identified friedelin synthase, TwOSC4, failed to produce friedelin when expressed in yeast. The usefulness of this approach was also demonstrated by the fact that when CYP712K2 and CYP712K3 were co-expressed with a friedelin synthase, they were able to produce polpunonic acid in tobacco but not in yeast. The inability to observe friedelin oxygenation by CYP712K2 and CYP712K3 in yeast could be due to differences in translational efficiency, mRNA or protein stability. A possible downside of the approach can be the ability of endogenous tobacco enzymes to further modify the enzymatic products. For example, it is established that tobacco often glycosylates products of heterologous enzymes resulting in a multitude of glycoside products [61]. This can be circumvented by the use of glycosylase formulations, such as Viscozyme (SigmaAldrich) to deglycosylate the compounds to their original form prior to analysis.

The three CYP712K enzymes that we identified were all able to convert friedelin to two new compounds, 29-hydroxy-friedelin and polpunonic acid, when coexpressed with $\mathrm{TwOSC}_{4}$ in tobacco. This stepwise oxidation reaction likely follows the same pattern for carboxylic acid formation as previously observed in the wellcharacterized stepwise oxidation of $\beta$-amyrin to oleanolic acid [45]. First, oxidation of the methyl group to an alcohol, then to the corresponding aldehyde, and finally oxidation to a carboxylic acid. This pattern has previously been described for the oxidation of carbons 23, 24, 28, and 30 of an oleanane backbone [45, 62-65]. Although all three CYP712Ks identified here oxidize the C-29 position on friedelin, we noted that each of them produced a different ratio of 29-hydroxy-friedelin to polpunonic acid (Fig. 3). CYP712K1 appears to produce higher absolute amounts of polpunonic acid and exhibits a higher polpunonic acid to 29-hydroxy-friedelin ratio than CYP712K2 or CYP712K3. This type of differences in the efficacy of conversion of the intermediate alcohols by $\mathrm{P} 450 \mathrm{~s}$ has previously also been observed in the case of $\alpha$-amyrin, $\beta$-amyrin and lupeol C-28-oxidizing CYP716As [45, 46, 66].

In addition to friedelin synthase (TwOSC4), we also identified three other OSC enzymes. Two of these, $T w \mathrm{OSC} 1$ and $T w \mathrm{OSC} 2$, produce mainly $\beta$-amyrin, while the third one, TwOSC3, produces $\alpha$-amyrin. Triterpenoid compounds derived from $\beta$-amyrin, such as oleanolic acid, are widespread across most orders of higher plants [67]. In T. wilfordii, several oleanane type triterpenoids, many of which contain a carboxylic acid group at the C-29 position [68], have been reported, suggesting that these decorations could be formed by either CYP712K1, CYP712K2 and CYP712K3, or highly similar enzymes. Here, we show that CYP712K1 and CYP712K2 can turn products of TwOSC2 and TwOSC 3 into the new compounds, 7, 8 and 9 (Additional file 1: Figure S2). Although we did not confirm the structure of these compounds directly, we speculate that 7 is 29 -hydroxy$\beta$-amyrin and $\mathbf{8}$ is 29 -carboxy- $\beta$-amyrin, because they are produced only when the $\mathrm{P} 450 \mathrm{~s}$ are co-expressed with the two $\beta$-amyrin producing OSCs (Tw OSC1 and Tw OSC2). In addition, we hypothesize that $\mathbf{9}$ likely corresponds to 
29 -carboxy- $\alpha$-amyrin because it is only observed when CYP712K1 or CYP712K2 are co-expressed with the predominantly $\alpha$-amyrin producing TwOSC3. Moreover, we observe that CYP712K1 and CYP712K2 have different apparent substrate specificities for $\alpha$-amyrin and $\beta$-amyrin (Additional file 1: Figure S2). In combination with the $\beta$-amyrin-producing TwOSC2, CYP712K1 produces mostly 7 , while CYP712K2 mostly 8 . However, when both CYPs are present we observe mostly 8 , suggesting that 8 (putative 29 -carboxy- $\beta$-amyrin) may be a derivative of 7 (putative 29 -hydroxy- $\beta$-amyrin). According to this, it appears that CYP712K2 catalyzes efficiently all the steps until the formation of 29 -carboxy- $\beta$-amyrin, whereas CYP712K1 produces mostly 29 -hydroxy- $\beta$ amyrin. By contrast, when using friedelin as substrate, CYP712K1 produces mostly polpunonic acid, while CYP712K2 produces mostly 29-hydroxy-friedelin (Fig. 3). Thus, these findings suggest that friedelin is likely the preferred substrate for CYP712K1, while $\beta$-amyrin is likely the preferred substrate for CYP712K2. In addition, we observed that expression of CYP712K2 together with the $\alpha$-amyrin-producing TwOSC3 resulted in the production of 9 (putative 29-carboxy- $\alpha$-amyrin), whereas co-expression of CYP712K1 with TwOSC3 did not produce this compound. This observation suggests that CYP712K1 and CYP712K2 likely also have different preference for $\alpha$-amyrin.

Having identified a friedelin synthase and three P450s capable of performing what appears to be the first oxygenation step in celastrol biosynthesis, we set out to produce polpunonic acid in yeast. As TwOSC4 proved to be inactive when expressed in yeast, $K d$ FRS was chosen as a surrogate friedelin synthase because it had previously been shown to be functional in yeast [51]. Experiments with $K d$ FRS yielded a maximum titer of $0.12 \mathrm{mg} / \mathrm{L}$ of friedelin. This number is in line with the friedelin titers previously reported using non-engineered production strains $(0.05 \mathrm{mg} / \mathrm{mL}$ with $K d \mathrm{FRS} ; 0.1 \mathrm{mg} / \mathrm{mL}$ with MiFRS) [38]. Compared with the yields of other triterpenoids [69], these titers are relatively low. We interpret this as the result of inherent properties of friedelin itself, such as potential toxicity to yeast, or the mechanism of friedelin production by $K d F R S$, as friedelin is the last product of a long and complicated cycloisomerization cascade [33]. However, the recently published work of Zhou et al. [55], reports a titer of more than $2 \mathrm{mg} / \mathrm{L}$ from expressing KY885469 in strain BY4741 [70]. This suggests that culture conditions or extraction method may be responsible for the differences in the reported yields and indicates that there is potential for important further improvement of friedelin production titers.

In order to increase friedelin production in yeast three different yeast strains, including AM109 [49], AM238
[52] and AM254 (created in this study) were evaluated. AM254 was derived from AM238 by the deletion of $U B C 7$ [71], that encodes for an E2 ubiquitin conjugating enzyme active in the yeast ERAD [72, 73]. Ubc7p is needed for the ubiquitination of some membrane proteins, such as the sterol biosynthesis bottleneck enzyme Erg1p (squalene epoxidase) by the E2 ubiquitin ligase Doa10p [74], and for the feedback-regulated degradation of the key regulatory enzymes of the sterol pathway, Hmg1p and Hmg2p [53]. Thus, the friedelin titer improvements observed as a result of $U B C 7$ deletion are likely due to elevated levels of Erg1p, Hmg1p, and Hmg2p, resulting in increased flux to 2,3-oxidosqualene. Nevertheless, the possibility that $U B C 7$ deletion may also have additional effects, such as, for example, friedelin synthase stabilization, cannot be ruled out.

We established polpunonic acid production by coexpression of KdFRS, tHMG2, CYP712K1 and TwCPR1 in the strain AM254-5 (Fig. 7a). Friedelin and polpunonic acid were found exclusively in the pellet and not in the spent media. To further improve the production of friedelin and polpunonic acid and to introduce a convenient way of extracting these triterpenoids from spent yeast media, $\beta$-methyl-cyclodextrin was added to the yeast cultures. This method omits the chemical or mechanical homogenization of cells and, thereby, considerably shortens the time required for sample preparation. Furthermore, as only the medium is extracted and not the whole cell content, it results in significantly lower background. Cyclodextrins are known to facilitate triterpenoid production leading to significant improvements in triterpenoid titers [54]. However, the exact mechanism by which cyclodextrins facilitate the excretion of triterpenoids is not yet known. In our experiments, adding cyclodextrins to the media did not have an apparent effect on total friedelin titers and friedelin was still found mostly in pellet and to a lesser extend in the media. However, the total polpunonic acid titer increased 2.8-fold compared to the cells not treated with cyclodextrin. In these cells, polpunonic acid was found mostly in the spent media (71\%) and to a lesser extent (29\%) in the cell pellet. This is well in line with a previous report where cyclodextrins were used to improve the production of the oxidized triterpenoid, 16-hydroxy- $\beta$-amyrin [54]. The different effect of cyclodextrins on friedelin and polpunonic acid accumulation could possibly be related to the different functional groups and polarity of the two compounds. Perhaps the carboxyl group on polpunonic acid contributes to hydrogen bonding with the $\mathrm{OH}$-groups of cyclodextrins. Alternatively, the presence of the carboxyl group may play a role in the interaction of polpunonic with the plasma membrane, which may be a critical factor for its extraction by cyclodextrins. 
In summary, we characterized four oxidosqualene cyclases, TwOSC1 as a $\beta$-amyrin synthase, Tw OSCC2 as a mixed $\beta$-amyrin and lupeol synthase, TwOSC3 as a mixed $\alpha$-amyrin and $\beta$-amyrin synthase and TwOSC4 as friedelin synthase. We also characterized CYP712K1, CYP712K2 and CYP712K3 as triterpenoid oxidizing enzymes acting on $\mathrm{C}-29$. These enzymes catalyze the sequential formation of 29-hydroxy-friedelin, 29-oxofriedelin, and polpunonic acid, and most likely the corresponding oxidations of $\alpha$ - and $\beta$-amyrin, and are the first members of the CYP712 family to be reported to function in terpenoid metabolism. Having elucidated the cyclization and first triple-oxidation step of celastrol biosynthesis, we established a platform for the production of polpunonic acid in yeast. These results pave the way for the discovery of the missing enzymes in celastrol biosynthesis and provides an important advancement in the efforts to produce celastrol using biotechnological methods.

\section{Conclusions}

In this study, we used a combination of database mining with functional screening of candidate genes in tobacco to elucidate missing steps of the celastrol biosynthetic pathway. The newly discovered enzymes enabled the synthesis of polpunonic acid in engineered yeast. These advances pave the way for the complete elucidation of celastrol biosynthesis and the production of this potent anti-obesity agent in microbial cell factories.

\section{Methods}

\section{Plant material}

Tripterygium wilfordii plants were obtained from Plantentuin Esveld (NL) and grown under greenhouse conditions at a day length of minimum $11 \mathrm{~h}$ and a temperature of minimum $12{ }^{\circ} \mathrm{C}$. Samples of root and leaf tissue where harvested and immediately ground in liquid nitrogen, then stored at $-80{ }^{\circ} \mathrm{C}$ until further use for metabolite analysis and RNA isolation.

\section{Root transcriptome mining using the MassBlast tool}

The root transcriptome previously described by Hansen et al. [39] was mined using MassBlast, version 0.9.9 for win-32 [40]. MassBlast identifies and ranks putative homologs of entries in a custom-made query database. Separate query databases were used to identify candidate OSCs (the query database file contained only accession BAG82628; AtBAS) and candidate P450s (the query database was the P450 reference database of Zerbe et al. [43]). In the user.yml file, "engine" was set to tblastn, "-evalue" set to 1, "identity: min:" set to 0.35 , "prune_identical: list:" set to-nt_db_longest_orf and otherwise default settings. The output tables were subsequently manually filtered and sorted.

\section{Cloning}

Transcript specific primers for candidate OSCs were used in an initial amplification from cDNA (SuperScript ${ }^{\circledR}$ III First-Strand Synthesis System; ThermoFisher; Catalog No. 18080051) prepared from in house T. wilfordii root RNA (Spectrum Plant Total RNA Kit; Sigma Aldrich; product \# STRN50). All possible inter-contig combinations of forward and reverse primers were in addition tested. Gel purified (QIAquick Gel Extraction Kit; QIAGEN; Catalog No. 28706) amplicons of expected size were subsequently used as templates for amplifications using primers designed for USER cloning. Resulting amplicons of expected size were gel purified and cloned, using USER cloning, into the USER compatible destination vector, pCAMBIA-1300-35Su (encoding kanamycin resistance), previously used for transient gene expression in tobacco [42]. Primers are listed in Additional file 1: Table S1.

Transcript specific primers of candidate $\mathrm{P} 450$ s were used in an initial amplification from root derived cDNA except for seven candidates that were amplified from leaf cDNA (Additional file 1: Table S1). After blunt end ligation of gel purified amplicons of expected size into pJET1.2/blunt (Thermo Fisher Scientific Inc.; Cat\# K1231), resulting constructs were used as template for another amplification using primers designed for USER cloning. Gel purified amplicons of expected size were USER-cloned into pCAMBIA-1300-35Su. Some constructs were directly obtained by amplification from cDNA with USER compatible primers (indicated in Additional file 1: Table S1).

Yeast expression constructs were produced with USER cloning or restriction enzyme cloning of candidates and other parts into the yeast expression vectors $\mathrm{pESC}$ LEU or pESC-TRP (Agilent Technologies, Cat. \# 217452 and 217453) or pUUS (pESC-URA-USER) [75] according to Additional file 1: Table S2. Coding sequences for CYP712K1, CYP712K2, CYP712K3, TwOSC1, TwOSC2, TwOSC3, TwOSC4 and TwCPR1 were deposited in GenBank under accession numbers MN621243-MN621250, respectively.

\section{Transient co-expression in tobacco leaves}

Tripterygium wilfordii OSCs and/or candidate P450s were transiently (co-)expressed in tobacco leaves, together with the gene silencing suppressor p19 [76] and the Coleus forskohlii 1-deoxy-D-xylulose 5-phosphate 
synthase (CfDXS; elevating isoprenoid diphosphate precursor pool $[27,77])$, essentially according to a previously established protocol [78]. Briefly, harvested cultures of transformed Agrobacterium tumefaciens strain AGL-1 [78] were adjusted to $\mathrm{OD}_{600}=1$ in water and mixed 1:1 in respective gene combinations before infiltrated. Metabolites were extracted 6-8 days post infiltration from two leaf discs $(\varnothing 3 \mathrm{~cm}, 1$ disc per leaf) per gene combination in a desired solvent (see analytical procedures for details) and analyzed. As background controls, p19 and CfDXS were co-expressed alone. Plant material for purification of compounds $\mathbf{5}$ and $\mathbf{6}$ were prepared by largescale vacuum infiltrations (48 plants per compound) as previously described [79]. Overnight cultures $(15 \mathrm{~mL})$ of transformed A. tumefaciens were used as starter cultures for subsequent cultures of $200 \mathrm{~mL}$. These were grown overnight to $\mathrm{OD}_{600}>1$ before harvested, adjusted to $\mathrm{OD}_{600}=1$ using water, and mixed in equal volumes to obtain the respective gene combinations prior to infiltration. Infiltrated leafs were harvested 8 days post infiltration and stored at $-20^{\circ} \mathrm{C}$ until further used.

\section{Extraction and isolation of compounds 5 and 6}

Tobacco leaves containing compounds, 5 and $\mathbf{6}$ were harvested, ground in liquid nitrogen and extracted three times with $200 \mathrm{~mL}$ of ethyl acetate $(1 \mathrm{~h}$ of shaking for each). Total crude ethyl acetate extracts were dried by rotor evaporation. Compound $\mathbf{5}$ was separated by repeated Silica gel column chromatography eluted with $\mathrm{CH}_{2} \mathrm{Cl}_{2}: \mathrm{MeOH}$ (95:5), and further purified by Sephadex LH-20 (MeOH). In a resulting fraction, compound 5 formed crystals that were washed to purity with hexane. For isolation of $\mathbf{6}$, the dry residue was subjected to repeated silica gel column chromatography successively eluted with $\mathrm{CH}_{2} \mathrm{Cl}_{2}$ :acetone $(98: 2,9: 1,4: 1,1: 1,0: 1)$ and acetone:ethyl acetate $(9: 1,1: 1,0: 1)$. In a resulting fraction, compound $\mathbf{6}$ formed crystals that were washed to purity in acetone (final yield $=2.5 \mathrm{mg}$ ).

\section{Extraction of $T$. wilfordii root and leaf metabolites}

Plant tissue (25-50 mg) was ground in liquid nitrogen, transferred to a glass vial, and extracted with $1 \mathrm{~mL}$ methanol for $1 \mathrm{~h}$ with shaking at RT. The residue was spun down and the supernatant diluted 1:5 with methanol before analyzed with LC-ESI-MS. Plant tissues were extracted and analyzed in three biological replicates (i.e. from three individual plants).

\section{Construction of yeast strains and yeast expression of candidates}

To create strain AM254, a disruption cassette for $U B C 7$ in strain AM238 was created. A large PCR reaction $(300 \mu \mathrm{L})$ was prepared using vector pUG27 as template,
MyTaq $^{\mathrm{TM}}$ DNA Polymerase (Bioline) and the primers UBC7 pUG-F: and UBC7 pUG-R (Additional file 1: Table S1). PCR cycling conditions were: initial denaturation at $95{ }^{\circ} \mathrm{C}$ for $1 \mathrm{~min}$ followed by 35 cycles of denaturation at $95^{\circ} \mathrm{C}$ for $30 \mathrm{~s}$, annealing at $52^{\circ} \mathrm{C}$ for $30 \mathrm{~s}$ and extension at $72{ }^{\circ} \mathrm{C}$ for $1 \mathrm{~min}$ and 1 cycle of extension at $72{ }^{\circ} \mathrm{C}$ for $5 \mathrm{~min}$. The amplicon was gel purified and precipitated with phenol/chloroform extraction, chloroform extraction (twice), ethanol precipitation, and finally air dried. Strain AM238 was transformed with the pelleted amplicon as described above and the transformation mixture was plated on $\mathrm{Glu} / \mathrm{CM}$-His agar for selection and incubated for 3 days at $30{ }^{\circ} \mathrm{C}$. Single colonies of the transformants were gridded in a new Glu/CM-His agar plate. Genomic DNA was extracted from $50 \mathrm{~mL}$ overnight cultures originating from eight different yeast colonies. PCR was performed for verification of cassette integration with MyTaq ${ }^{\mathrm{TM}}$ DNA Polymerase (Bioline), gDNA as template and the primers UBC7_pUG_R and UBC7_prom_F. Five correct clones were identified and verified by sequencing, and one of these was carried forward to excise the loxP-his-loxP fragment by yeast transformation with the Cre recombinase-expressing plasmid pB227/Gal-Cre and growth in Gal-Raff/CM-Leu agar broth. Cells cured for the plasmid were tested for loss of HIS5 marker by PCR, thereby generating strain AM254.

The yeast strains listed in Table 1 were produced by transforming the parent strains with yeast expression plasmids using the lithium acetate method [80]. For the production of friedelin and derivatives, pre-cultures of the strains were grown until saturation in synthetic defined media including $2 \%$ glucose. Then, the cells were washed with water and inoculated into $10 \mathrm{~mL}$ synthetic defined media with $2 \%$ galactose and $1 \%$ raffinose with or without $10 \mathrm{mM} \beta$-methyl cyclodextrins and grown for $96 \mathrm{~h}$ at $30^{\circ} \mathrm{C}$ and $150 \mathrm{rpm}$.

\section{Extraction of triterpenoids from yeast cells and media}

Cell pellets from $10 \mathrm{~mL}$ yeast cultures were disrupted by saponification by addition of $10 \mathrm{~mL} 20 \% \mathrm{KOH} / 25 \%$ ethanol and then incubated for $1 \mathrm{~h}$ at $90{ }^{\circ} \mathrm{C}$. Subsequently the saponified cells were extracted three times with $5 \mathrm{~mL}$ of hexane.

\section{Compound extraction from tobacco leaves}

One leaf disc $(\varnothing 3 \mathrm{~cm})$ was ground in an Eppendorf tube and mixed with $0.6 \mathrm{~mL} 50 \mathrm{mM}$ sodium acetate, $\mathrm{pH} 5.3$. To this, $20 \mu \mathrm{L}$ of Viscozyme (Sigma-Aldrich) or water (control) was added prior to shaking for $1 \mathrm{~h}$ at room temperature. The Viscozyme treated sample appeared 
viscous compared to control. Metabolites were extracted in $1 \mathrm{~mL}$ ethyl acetate by shaking for $5 \mathrm{~min}$ and the upper layer was transferred to new vials. The solvent was evaporated under a stream of nitrogen and the residue re-suspended in $1 \mathrm{~mL}$ methanol and analyzed by LC-ESI-MS.

\section{Analytical procedures}

GC-MS analyses of non-derivatized samples were performed on a Shimadzu GC-MS-QP2010 Ultra fitted with an Agilent HP-5MS column (Length: $20 \mathrm{~m}$; Thickness: $0.18 \mu \mathrm{m}$; Diameter: $0.18 \mu \mathrm{m})$. The injection volume was $1 \mu \mathrm{L}$ at $250{ }^{\circ} \mathrm{C}$ (splitless mode) and the GC program was as follows: $60^{\circ} \mathrm{C}$ for $1 \mathrm{~min}$, ramp at the rate of $30{ }^{\circ} \mathrm{C} / \mathrm{min}$ to $260{ }^{\circ} \mathrm{C}$, ramp at the rate of $5{ }^{\circ} \mathrm{C} /$ min to $300{ }^{\circ} \mathrm{C}$, ramp at the rate of $30{ }^{\circ} \mathrm{C} / \mathrm{min}$ to $320^{\circ} \mathrm{C}$, hold for $3 \mathrm{~min}$.

Alternatively, GC-MS analysis was carried on a DB-5 column using the following program: Injection volume was $2 \mu \mathrm{L}$. The initial temperature $60{ }^{\circ} \mathrm{C}$, ramp to $300{ }^{\circ} \mathrm{C}$ with a rate of $10{ }^{\circ} \mathrm{C} / \mathrm{min}$, ramp to $320{ }^{\circ} \mathrm{C}$ with a rate of $3{ }^{\circ} \mathrm{C} / \mathrm{min}$, hold for $3.5 \mathrm{~min}$.

Sample derivatization with trimethylsilyl cyanide was automated using a GERSTEL MultiPurpose Sampler (MPS) with DualRait WorkStation integrated to a GC-MS system from Agilent (7890A GC and an Agilent 5975C series MSD). Separation of derivatized samples was achieved using an Agilent HP- 5MS column $(30 \mathrm{~m} \times 250 \mu \mathrm{m} \times 0.25 \mu \mathrm{m})$ with hydrogen as carrier gas at a constant flow rate of $1.2 \mathrm{~mL} / \mathrm{min}$. The GC oven temperature program was as follows: initial temperature, $60{ }^{\circ} \mathrm{C}$; equilibration time, $1 \mathrm{~min}$; heating rate, $12{ }^{\circ} \mathrm{C} / \mathrm{min}$; end temperature, $310^{\circ} \mathrm{C}$; hold time, $6 \mathrm{~min}$; and post-run time, $5 \mathrm{~min}$ at $60^{\circ} \mathrm{C}$.

Qualitative LC-ESI-MS analysis was performed on the Dionex UltiMate ${ }^{\circledR} 3000$ Quaternary Rapid Separation UHPLC focused system (Thermo Fisher Scientific, Germering, Germany) equipped with a Phenomenex Kinetex XB-C18 column $(100 \mathrm{~mm} \times 2.1 \mathrm{~mm}$ i.d., $1.7 \mu \mathrm{m}$ particle size, $100 \AA$ pore size) (Phenomenex, Inc., Torrance, CA, USA). The column was operated at $40{ }^{\circ} \mathrm{C}$, and the flow rate was maintained at $0.3 \mathrm{~mL} / \mathrm{min}$. The mobile phases were water (A) and $100 \%$ acetonitrile (B), both acidified with $0.05 \%$ formic acid. Separations were performed using the following gradient profile: $0 \mathrm{~min}$, $37 \%$ B; 11 min, $80 \%$ B; 21 min, 90\% B; 22 min, 100\% B; $27 \mathrm{~min}, 100 \%$ B; $28 \mathrm{~min}, 37 \%$ B. The column outlet was connected to a Bruker Daltonics Compact QqTOF mass spectrometer equipped with electrospray ionization (ESI) interface (Bruker Daltonics, Bremen, Germany). Mass spectra were acquired in positive ion mode, using a capillary voltage of $4500 \mathrm{~V}$, an end plate offset of $-500 \mathrm{~V}$, a drying temperature of $250{ }^{\circ} \mathrm{C}$, a nebulizer pressure of 1.2 bars, and a drying gas flow of $8 \mathrm{~L} / \mathrm{min}$. Sodium formate solution (internal standard) was injected at the beginning of each chromatographic run and the LC-MS raw data was calibrated against these sodium clusters using the Data Analysis 4.1 (Bruker Daltonics) software program. Quantitative LC-APCI-MS was performed with the same equipment and program except that atmospheric pressure chemical ionization (APCI) interface (Bruker Daltonics, Bremen, Germany) was used instead and mobile phase (B) was 50\% acetonitrile-50\% methanol with $0.05 \%$ formic acid.

\section{Standards}

Celastrol, $\alpha$-amyrin, $\beta$-amyrin, lupeol, betulinic acid, hederagenin, oleanolic acid and friedelin were purchased from Sigma-Aldrich.

\section{NMR analysis}

All NMR spectra were recorded at $300 \mathrm{~K}$ in $\mathrm{CDCl}_{3}$. NMR experiments for compound $\mathbf{5}$ and $\mathbf{6}$ were performed with a $600 \mathrm{MHz}$ Bruker Avance III NMR equipped with a $5 \mathrm{~mm}$ broad band probe (Bruker Biospin) optimized for ${ }^{1} \mathrm{H}$ and ${ }^{13} \mathrm{C}$. All experiments were acquired in automation (temperature equilibration to $300 \mathrm{~K}$, optimization of lock parameters, gradient shimming, and setting of receiver gain). One-dimensional ${ }^{1} \mathrm{H}$ and ${ }^{13} \mathrm{C}$ NMR spectra were acquired with $30^{\circ}$-pulses and $64 \mathrm{k}$ data points. IconNMR ver.4.2 (Bruker Biospin, Karlsruhe, Germany) was used for controlling automated sample change and acquisition of NMR data, whereas TopSpin ver. 3.5 (Bruker Biospin, Karlsruhe, Germany) was used for acquisition and processing of NMR data.

\section{Supplementary information}

Supplementary information accompanies this paper at https://doi. org/10.1186/s12934-020-1284-9.

\begin{abstract}
Additional file 1: Table S1. Clone and primer list. Table S2. Yeast expression constructs. Table S3. Assigned $1 \mathrm{C}$ and 13C NMR peaks for compound 5 and 6 . Figure S1. Comparison of the mass spectra of TMS derivatized TwOSC products from tobacco leaf co-infiltration experiments, with TMS derivatized authentic standards. Figure S2. CYP712K1 and CYP712K2 oxygenate the triterpene products of TwOSC2 and TwOSC3 in tobacco. Two leaf discs $(\varnothing 3 \mathrm{~cm})$ of leaves co-expressing the indicated enzymes were extracted in $1 \mathrm{~mL}$ ethyl acetate. A $0.15 \mathrm{~mL}$ aliquot of this extract was dried, TMS derivatized and analyzed by GC-MS. None of the novel peaks 7-9 had mass spectra or retention times matching any of the analyzed authentic standards (betulinic acid, hederagenin, or oleanolic acid; not shown). Figure S3. Comparison of LC-ESI-MS and LC-APCI-MS (base peak chromatograms) for the reliable quantification of friedelin and polpunonic acid. Authentic standards of friedelin and polpunonic acid (30 $\mu \mathrm{g} /$ $\mathrm{mL}$ ) were analyzed using the same LC-MS equipment and program with exception of ionization probe (ESI; black trace and $\mathrm{APCl}$; red trace).
\end{abstract}

\section{Acknowledgements}

We would like to thank Dr. David lan Pattison and Stephanie Petersen from the metabolomics platform of the Department of Plant and Environmental Sciences (University of Copenhagen, Denmark) for their support in GC-MS 
and LC-MS analysis, Dr. Bekzod Khakimov (Department of Food Science, University of Copenhagen) for support in CG-MS analysis, and Prof. Irina Borodina (Technical University of Denmark) for providing the pESC-USER vector set. We are grateful to Irini Pateraki and Allison Heskes (University of Copenhagen, Denmark) for helpful comments and discussions.

\section{Authors' contributions}

NLH: conceived the project, conducted database searches, cloned candidates for expression in tobacco and yeast, characterized candidates in tobacco, and drafted the manuscript. KM: yeast transformation and growth, cyclodextrin experiments, evaluation of the productivity of different yeast strains, method development, manuscript writing. Cl: experimental design, yeast transformations, yeast strain cultivation. AM: generation of strain AM254. AA: generation of strain AM254. YZ: structural elucidation of compounds. DS: NMR analysis, structural elucidation of compounds. MHR: initial evaluation of AM238 and AM254 strains, yeast strain preparation. BLM: experimental design. SB: experimental design, data analysis, manuscript writing. SCK: Experimental design, analysis of results, manuscript writing. All authors read and approved the final manuscript.

\section{Funding}

This work was supported by the Novo Nordisk Foundation (Grants NNF18OC0031872 to KM, NNF16OC0021616 to BLM, NNF17OC0027646 to SB and NNF16OC0021760 to SCK), the European Union Seventh Framework Programme [FP7/2007-2013] under grant agreement 613692-TriforC to SB, and the General Secretariat of Science and Technology Hellas (GSRT; Grant $11 \Sigma$ VN_3_770 to AMM and SCK).

\section{Availability of data and materials}

The datasets used and/or analyzed during the current study are available from the corresponding author on reasonable request.

\section{Ethics approval and consent to participate} Not applicable.

\section{Consent for publication}

Not applicable.

\section{Competing interests}

The authors declare that they have no competing interests.

\begin{abstract}
Author details
${ }^{1}$ Plant Biochemistry Section, Department of Plant and Environmental Sciences, University of Copenhagen, Thorvaldsensvej 40, 1871 Frederiksberg C, Denmark. ${ }^{2}$ Department of Drug Design and Pharmacology, Faculty of Health and Medical Sciences, University of Copenhagen, Universitetsparken 2, 2100 Copenhagen, Denmark. ${ }^{3}$ Institute of Applied BiosciencesCentre for Research and Technology Hellas (INAB-CERTH), P.O. Box 60361 57001 Thermi, Thessaloniki, Greece.
\end{abstract}

Received: 20 September 2019 Accepted: 14 January 2020 Published online: 28 January 2020

\section{References}

1. Olshansky SJ, et al. A potential decline in life expectancy in the United States in the 21st century. N Engl J Med. 2005;352:1138-45. https://doi. org/10.1056/NEJMsr043743.

2. Dietrich $\mathrm{MO}$, Horvath TL. Hypothalamic control of energy balance: insights into the role of synaptic plasticity. Trends Neurosci. 2013;36:6573. https://doi.org/10.1016/j.tins.2012.12.005

3. Myers MG Jr, Leibel RL, Seeley RJ, Schwartz MW. Obesity and leptin resistance: distinguishing cause from effect. Trends Endocrinol Metab TEM. 2010;21:643-51. https://doi.org/10.1016/j.tem.2010.08.002.

4. Halaas $J \mathrm{~L}$, et al. Physiological response to long-term peripheral and central leptin infusion in lean and obese mice. Proc Natl Acad Sci USA. 1997:94:8878-83.

5. Considine RV, et al. Serum immunoreactive-leptin concentrations in normal-weight and obese humans. N Engl J Med. 1996;334:292-5. https ://doi.org/10.1056/NEJM199602013340503.
6. Frederich $\mathrm{RC}$, et al. Leptin levels reflect body lipid content in mice: evidence for diet-induced resistance to leptin action. Nat Med. 1995;1:1311-4

7. Liu J, Lee J, Salazar Hernandez MA, Mazitschek R, Ozcan U. Treatment of obesity with celastrol. Cell. 2015;161:999-1011. https://doi.org/10.1016/j. cell.2015.05.011.

8. Ma X, et al. Celastrol protects against obesity and metabolic dysfunction through activation of a HSF1-PGC1alpha transcriptional axis. Cell Metab. 2015:22:695-708. https://doi.org/10.1016/j.cmet.2015.08.005.

9. Hu M, et al. Celastrol-induced Nur77 Interaction with TRAF2 alleviates inflammation by promoting mitochondrial ubiquitination and autophagy. Mol Cell. 2017;66:141-53. https://doi.org/10.1016/j.molce 1.2017.03.008

10. Uttarkar S, et al. Targeting acute myeloid leukemia with a small molecule inhibitor of the Myb/p300 interaction. Blood. 2016;127:1173-82. https:// doi.org/10.1182/blood-2015-09-668632.

11. Hassane DC, et al. Discovery of agents that eradicate leukemia stem cells using an in silico screen of public gene expression data. Blood. 2008;111:5654-62. https://doi.org/10.1182/blood-2007-11-126003.

12. Freudlsperger $C$, et al. TGF-beta and NF-kappaB signal pathway cross-talk is mediated through TAK1 and SMAD7 in a subset of head and neck cancers. Oncogene. 2013;32:1549-59. https://doi.org/10.1038/onc.2012.171.

13. Hieronymus $\mathrm{H}$, et al. Gene expression signature-based chemical genomic prediction identifies a novel class of HSP90 pathway modulators. Cancer Cell. 2006;10:321-30. https://doi.org/10.1016/j.ccr.2006.09.005.

14. Pang $X$, et al. Celastrol suppresses angiogenesis-mediated tumor growth through inhibition of AKT/mammalian target of rapamycin pathway. Cancer Res. 2010;70:1951-9. https://doi.org/10.1158/0008-5472. CAN-09-3201.

15. Yang H, Chen D, Cui QC, Yuan X, Dou QP. Celastrol, a triterpene extracted from the Chinese "Thunder of God Vine," is a potent proteasome inhibitor and suppresses human prostate cancer growth in nude mice. Cancer Res. 2006;66:4758-65. https://doi.org/10.1158/0008-5472.CAN-05-4529.

16. Sethi G, Ahn KS, Pandey MK, Aggarwal BB. Celastrol, a novel triterpene, potentiates TNF-induced apoptosis and suppresses invasion of tumor cells by inhibiting NF-kappaB-regulated gene products and TAK1mediated NF-kappaB activation. Blood. 2007;109:2727-35. https://doi. org/10.1182/blood-2006-10-050807.

17. Nanjundaiah SM, et al. Celastrus and its bioactive celastrol protect against bone damage in autoimmune arthritis by modulating osteoimmune cross-talk. J Biol Chem. 2012;287:22216-26. https://doi.org/10.1074/jbc. M112.356816.

18. Mu TW, et al. Chemical and biological approaches synergize to ameliorate protein-folding diseases. Cell. 2008;134:769-81. https://doi.org/10.1016/j. cell.2008.06.037.

19. Yang C, et al. Celastrol increases glucocerebrosidase activity in Gaucher disease by modulating molecular chaperones. Proc Natl Acad Sci USA. 2014;111:249-54. https://doi.org/10.1073/pnas.1321341111.

20. Lange BM, et al. Identification and localization of specialized metabolites in tripterygium roots. Plant Physiol. 2016. https://doi.org/10.1104/ pp.15.01593.

21. Zhuo R, et al. Rapid simultaneous quantitative determination of terpenoids in Tripterygium wilfordii Hook F by ultra-high-performance liquid chromatography coupled with quadrupole time-of-flight mass spectrometry. Anal Methods. 2013;5:2046-52.

22. Camelio AM, Johnson TC, Siegel D. Total synthesis of celastrol, development of a platform to access celastroid natural products. J Am Chem Soc. 2015;137:11864-7. https://doi.org/10.1021/jacs.5b06261.

23. Luo Y, et al. Engineered biosynthesis of natural products in heterologous hosts. Chem Soc Rev. 2015;44:5265-90. https://doi.org/10.1039/c5cs0 0025d.

24. Paddon CJ, Keasling JD. Semi-synthetic artemisinin: a model for the use of synthetic biology in pharmaceutical development. Nat Rev Microbiol. 2014;12:355-67. https://doi.org/10.1038/nrmicro3240.

25. Kotopka BJ, Li Y, Smolke CD. Synthetic biology strategies toward heterologous phytochemical production. Nat Prod Rep. 2018;35:902-20. https:// doi.org/10.1039/c8np00028j.

26. Miettinen $\mathrm{K}$, et al. The seco-iridoid pathway from Catharanthus roseus. Nat Commun. 2014;5:3606. https://doi.org/10.1038/ncomms4606.

27. Luo D, et al. Oxidation and cyclization of casbene in the biosynthesis of Euphorbia factors from mature seeds of Euphorbia lathyris L. Proc Natl 
Acad Sci USA. 2016;113:E5082-9. https://doi.org/10.1073/pnas.16075 04113.

28. Pateraki I, et al. Total biosynthesis of the cyclic AMP booster forskolin from Coleus forskohlii. eLife. 2017. https://doi.org/10.7554/elife.23001.

29. Huang A, et al. A specialized metabolic network selectively modulates Arabidopsis root microbiota. Science. 2019. https://doi.org/10.1126/scien ce.aau6389.

30. Brown DJ, Dupont FM. Lipid composition of plasma membranes and endomembranes prepared from roots of barley (Hordeum vulgare L.): effects of salt. Plant Physiol. 1989;90:955-61. https://doi.org/10.1104/ pp.90.3.955.

31. van Meer G, Voelker DR, Feigenson GW. Membrane lipids: where they are and how they behave. Nat Rev Mol Cell Biol. 2008;9:112-24. https://doi. org/10.1038/nrm2330.

32. Paddon CJ, et al. High-level semi-synthetic production of the potent antimalarial artemisinin. Nature. 2013;496:528-32.

33. Thimmappa R, Geisler K, Louveau T, O'Maille P, Osbourn A. Triterpene biosynthesis in plants. Annu Rev Plant Biol. 2014;65:225-57. https://doi. org/10.1146/annurev-arplant-050312-120229.

34. Hamberger B, Bak S. Plant P450s as versatile drivers for evolution of species-specific chemical diversity. Philos Trans R Soc Lond Ser B Biol Sci. 2013;368:20120426. https://doi.org/10.1098/rstb.2012.0426.

35. Kawai Y, Ono E, Mizutani M. Evolution and diversity of the 2-oxoglutaratedependent dioxygenase superfamily in plants. Plant J. 2014;78:328-43. https://doi.org/10.1111/tpj.12479.

36. Seki H, Tamura K, Muranaka T. P450s and UGTs: key players in the structural diversity of Triterpenoid Saponins. Plant Cell Physiol. 2015;56:1463-71. https://doi.org/10.1093/pcp/pcv062.

37. Souza-Moreira TM, et al. Friedelin synthase from Maytenus ilicifolia: leucine 482 plays an essential role in the production of the most rearranged pentacyclic triterpene. Scientific Rep. 2016;6:36858. https://doi.org/10.1038/ srep36858.

38. Alves TB, Souza-Moreira TM, Valentini SR, Zanelli CF, Furlan M. Friedelin in Maytenus ilicifolia is produced by friedelin synthase isoforms. Molecules. 2018. https://doi.org/10.3390/molecules 23030700.

39. Hansen NL, et al. The terpene synthase gene family in Tripterygium wilfordii harbors a labdane-type diterpene synthase among the monoterpene synthase TPS-b subfamily. Plant J. 2017;89:429-41. https://doi. org/10.1111/tpj.13410.

40. Veríssimo A, Bassard J-E, Julien-Laferrière A, Sagot M-F, Vinga S. MassBlast: a workflow to accelerate RNA-seq and DNA database analysis. BioRxiv. 2017. https://doi.org/10.1101/131953.

41. Shibuya M, et al. Identification of a product specific beta-amyrin synthase from Arabidopsis thaliana. Plant Physiol Biochem PPB. 2009;47:26-30. https://doi.org/10.1016/j.plaphy.2008.09.007.

42. Nour-Eldin HH, Hansen BG, Norholm MH, Jensen JK, Halkier BA. Advancing uracil-excision based cloning towards an ideal technique for cloning PCR fragments. Nucleic Acids Res. 2006;34:e122. https://doi.org/10.1093/ nar/gkl635.

43. Zerbe P, et al. Gene discovery of modular diterpene metabolism in nonmodel systems. Plant Physiol. 2013;162:1073-91. https://doi.org/10.1104/ pp.113.218347.

44. Ro DK, Arimura G, Lau SY, Piers E, Bohlmann J. Loblolly pine abietadienol/ abietadienal oxidase PtAO (CYP720B1) is a multifunctional, multisubstrate cytochrome P450 monooxygenase. Proc Natl Acad Sci USA. 2005;102:8060-5.

45. Fukushima EO, et al. CYP716A subfamily members are multifunctional oxidases in triterpenoid biosynthesis. Plant Cell Physiol. 2011;52:2050-61. https://doi.org/10.1093/pcp/pcr146.

46. Khakimov B, et al. Identification and genome organization of saponin pathway genes from a wild crucifer, and their use for transient production of saponins in Nicotiana benthamiana. Plant J Cell Mol Biol. 2015;84:478-90. https://doi.org/10.1111/tpj.13012.

47. Alves JS, et al. Complete assignment of the $1 \mathrm{H}$ and $13 \mathrm{C}$ NMR spectra of four triterpenes of the ursane, artane, lupane and friedelane groups. Magn Reson Chem. 2000;38:201-6. https://doi.org/10.1002/(sici)1097458x(200003)38:3\%3c201:aid-mrc622\%3e3.0.co;2-0.

48. Itokawa $\mathrm{H}$, et al. Triterpenes from Maytenus Ilicifolia. Phytochemistry (Oxford). 1991;30:3713-6.
49. Ignea $\mathrm{C}$, et al. Positive genetic interactors of HMG2 identify a new set of genetic perturbations for improving sesquiterpene production in Saccharomyces cerevisiae. Microb Cell Fact. 2012;11:162.

50. Trikka FA, et al. Combined metabolome and transcriptome profiling provides new insights into diterpene biosynthesis in S. pomifera glandular trichomes. BMC Genom. 2015;16:935. https://doi.org/10.1186/s1286 4-015-2147-3.

51. Wang Z, Yeats T, Han H, Jetter R. Cloning and characterization of oxidosqualene cyclases from Kalanchoe daigremontiana: enzymes catalyzing up to 10 rearrangement steps yielding friedelin and other triterpenoids. J Biol Chem. 2010;285:29703-12. https://doi.org/10.1074/jbc.M109.098871.

52. Trikka FA, et al. Iterative carotenogenic screens identify combinations of yeast gene deletions that enhance sclareol production. Microb Cell Fact. 2015;14:60. https://doi.org/10.1186/s12934-015-0246-0.

53. Hampton RY, Bhakta H. Ubiquitin-mediated regulation of 3-hydroxy3-methylglutaryl-CoA reductase. Proc Natl Acad Sci USA. 1997;94:129448. https://doi.org/10.1073/pnas.94.24.12944.

54. Moses T, et al. Combinatorial biosynthesis of sapogenins and saponins in Saccharomyces cerevisiae using a C-16alpha hydroxylase from Bupleurum falcatum. Proc Natl Acad Sci USA. 2014;111:1634-9. https://doi. org/10.1073/pnas.1323369111.

55. Zhou J, et al. Friedelane-type triterpene cyclase in celastrol biosynthesis from Tripterygium wilfordii and its application for triterpenes biosynthesis in yeast. N Phytol. 2019. https://doi.org/10.1111/nph.15809.

56. Nelson DR, Ming R, Alam M, Schuler MA. Comparison of cytochrome P450 genes from six plant genomes. Trop Plant Biol. 2008;1:216-35. https //doi.org/10.1007/s12042-008-9022-1.

57. Field B, Osbourn AE. Metabolic diversification-independent assembly of operon-like gene clusters in different plants. Science. 2008;320:543-7. https://doi.org/10.1126/science.1154990.

58. Castillo DA, Kolesnikova MD, Matsuda SP. An effective strategy for exploring unknown metabolic pathways by genome mining. J Am Chem Soc. 2013;135:5885-94. https://doi.org/10.1021/ja401535g.

59. Orij R, et al. Genome-wide analysis of intracellular pH reveals quantitative control of cell division rate by $\mathrm{pH}(\mathrm{c})$ in Saccharomyces cerevisiae. Genome Biol. 2012;13:R80. https://doi.org/10.1186/gb-2012-13-9-r80.

60. Martiniere A, et al. Uncovering pH at both sides of the root plasma membrane interface using noninvasive imaging. Proc Natl Acad Sci USA. 2018;115:6488-93. https://doi.org/10.1073/pnas.1721769115.

61. Dong L, Jongedijk E, Bouwmeester H, Van Der Krol A. Monoterpene biosynthesis potential of plant subcellular compartments. N Phytol. 2016:209:679-90. https://doi.org/10.1111/nph.13629.

62. Moses T, Thevelein JM, Goossens A, Pollier J. Comparative analysis of CYP93E proteins for improved microbial synthesis of plant triterpenoids. Phytochemistry. 2014;108:47-56. https://doi.org/10.1016/j.phyto chem.2014.10.002.

63. Biazzi E, et al. CYP72A67 catalyzes a key oxidative step in medicago truncatula hemolytic saponin biosynthesis. Mol Plant. 2015;8:1493-506. https ://doi.org/10.1016/j.molp.2015.06.003.

64. Seki $\mathrm{H}$, et al. Triterpene functional genomics in licorice for identification of CYP72A154 involved in the biosynthesis of glycyrrhizin. Plant Cell. 2011;23:4112-23. https://doi.org/10.1105/tpc.110.082685.

65. Liu Q, et al. The cytochrome P450 CYP72A552 is key to production of hederagenin-based saponins that mediate plant defense against herbivores. N Phytol. 2019;222:1599-609. https://doi.org/10.1111/nph.15689.

66. Yasumoto S, Fukushima EO, Seki H, Muranaka T. Novel triterpene oxidizing activity of Arabidopsis thaliana CYP716A subfamily enzymes. FEBS Lett. 2016;590:533-40. https://doi.org/10.1002/1873-3468.12074.

67. Vincken JP, Heng L, de Groot A, Gruppen H. Saponins, classification and occurrence in the plant kingdom. Phytochemistry. 2007;68:275-97. https ://doi.org/10.1016/j.phytochem.2006.10.008.

68. Lange $\mathrm{BM}$, et al. Integrative approaches for the identification and localization of specialized metabolites in tripterygium roots. Plant Physiol. 2017;173:456-69. https://doi.org/10.1104/pp.15.01593.

69. Dai Z, et al. Producing aglycons of ginsenosides in bakers'yeast. Scientific Rep. 2014;4:3698. https://doi.org/10.1038/srep03698.

70. Brachmann CB, et al. Designer deletion strains derived from Saccharomyces cerevisiae S288C: a useful set of strains and plasmids for PCR-mediated gene disruption and other applications. Yeast. 1998;14:115-32. https ://doi.org/10.1002/(SICI) 1097-0061(19980130)14:2\%3C115:AID-YEA20 4\%3e3.0.CO:2-2. 
71. Swanson R, Locher M, Hochstrasser M. A conserved ubiquitin ligase of the nuclear envelope/endoplasmic reticulum that functions in both ER-associated and Matalpha2 repressor degradation. Genes Dev. 2001;15:2660-74. https://doi.org/10.1101/gad.933301.

72. Brodsky JL, Skach WR. Protein folding and quality control in the endoplasmic reticulum: recent lessons from yeast and mammalian cell systems. Curr Opin Cell Biol. 2011;23:464-75. https://doi.org/10.1016/j. ceb.2011.05.004.

73. Federovitch CM, et al. Genetic and structural analysis of Hmg2p-induced endoplasmic reticulum remodeling in Saccharomyces cerevisiae. Mol Biol Cell. 2008;19:4506-20. https://doi.org/10.1091/mbc.E07-11-1188.

74. Foresti O, Ruggiano A, Hannibal-Bach HK, Ejsing CS, Carvalho P. Sterol homeostasis requires regulated degradation of squalene monooxygenase by the ubiquitin ligase Doa10/Teb4. eLife. 2013;2:e00953. https:// doi.org/10.7554/elife.00953.

75. Jensen NB, et al. EasyClone: method for iterative chromosomal integration of multiple genes in Saccharomyces cerevisiae. FEMS Yeast Res. 2014;14:238-48. https://doi.org/10.1111/1567-1364.12118.

76. Baulcombe DC, Molnar A. Crystal structure of p19-a universal suppressor of RNA silencing. Trends Biochem Sci. 2004;29:279-81. https://doi. org/10.1016/j.tibs.2004.04.007.
77. Bruckner K, Tissier A. High-level diterpene production by transient expression in Nicotiana benthamiana. Plant methods. 2013;9:46. https://doi. org/10.1186/1746-4811-9-46.

78. Bach SS et al. In: Rodríguez-Concepción M, editor. Plant isoprenoids: methods and protocols. New York: Springer; 2014. p. 245-55.

79. Sainsbury F, Saxena P, Geisler K, Osbourn A, Lomonossoff GP. Using a virus-derived system to manipulate plant natural product biosynthetic pathways. Methods Enzymol. 2012;517:185-202. https://doi.org/10.1016/ b978-0-12-404634-4.00009-7.

80. Gietz RD, Schiestl RH. High-efficiency yeast transformation using the LiAc/SS carrier DNA/PEG method. Nat Protoc. 2007;2:31-4. https://doi. org/10.1038/nprot.2007.13

\section{Publisher's Note}

Springer Nature remains neutral with regard to jurisdictional claims in published maps and institutional affiliations.
Ready to submit your research? Choose BMC and benefit from:

- fast, convenient online submission

- thorough peer review by experienced researchers in your field

- rapid publication on acceptance

- support for research data, including large and complex data types

- gold Open Access which fosters wider collaboration and increased citations

- maximum visibility for your research: over 100M website views per year

At BMC, research is always in progress.

Learn more biomedcentral.com/submissions 